\title{
The effectiveness of combined extracorporeal shockwave therapy and exercise for plantar heel pain: A systematic review
}

Ian Burton MSc, CSCS.

Physiotherapist, Angus HSCP, NHS Tayside, Dundee, United Kingdom

Please cite as: Burton, I. (2020). The effectiveness of combined extracorporeal shockwave therapy and exercise for plantar heel pain: A systematic review. SportRxiv doi: 10.31236/osf.io/mc85d

\section{ABSTRACT}

Background: Plantar heel pain (PHP) is a common musculoskeletal disorder, with both extracorporeal shockwave therapy (ESWT) and specific exercise such as plantar fascia specific stretching shown to be effective treatments. This review aimed to evaluate the effectiveness of combined ESWT and exercise interventions versus other interventions in treating PHP.

Methods: A systematic review of effectiveness was conducted, adhering to the PRISMA guidelines. Five databases were searched for studies published between 
January 2000 and March 2020, with 12 studies meeting the inclusion criteria. The Grading of Recommendations Assessment Development and Evaluation (GRADE) framework was used to determine quality of recommendations.

Results: The 12 included studies ( $\mathrm{n}=861$ ) compared ESWT and stretching with various other treatments. Due to clinical and methodological heterogeneity, pooling of data was not possible, and a narrative synthesis of findings was provided. There was high quality evidence that combined ESWT and stretching interventions are more effective than those using either alone or botulinum toxin injections, and low-quality evidence of superiority versus ultrasound and stretching. There was moderate quality evidence that combined ESWT and stretching is no more effective than corticosteroid injection (CSI), and high quality evidence that the combination is no more effective than blood-derived injection therapies, custom orthotics or low-level laser therapy (LLLT) combined with stretching. There is high quality evidence that the use of topical corticosteroid or laser therapy in combination with ESWT and stretching increases effectiveness compared to ESWT and stretching alone, and moderate quality evidence for the additive effective of dry needling.

Conclusions: Combined ESWT and stretching treatments are effective and may be recommended where they are available and practical to implement. Further high-quality studies with larger sample sizes and longer follow-up durations comparing combined interventions for PHP, including different exercise types such as resistance training are required.

Keywords: Exercise; Muscle Stretching Exercises; Extracorporeal Shockwave Therapy; High-Energy Shock Waves: Fasciitis, Plantar. 


\section{Introduction}

Recent research on the global burden of disease has highlighted how musculoskeletal disorders are a leading contributor to the global burden of disability and chronic pain [1]. Musculoskeletal disorders have an impact on a broad demographic spectrum of the population, result in extensive expenditure by healthcare systems and are a substantial societal burden [2-4]. However, servicelevel and health policy responses to this burden have been inadequate, with an integrated research and policy agenda required, including prioritising evidencebased effective treatments [5]. Chronic foot pain constitutes a large proportion of the musculoskeletal disease burden, with Plantar Heel Pain (PHP) causing up to $15 \%$ of all foot-related pain complaints and occurring in $10 \%$ of the population [69]. Symptoms of PHP include sharp heel pain commonly felt in the morning or after prolonged sitting, which can cause an impaired gait pattern and functional limitations $[10,11]$. The disorder presents like tendinopathy and results in chronic degeneration of plantar fascia tissues and collagen fibres rather than an acute inflammatory response and may result from excessive weight bearing or biomechanical abnormalities $[12,13]$. There are several commonly used clinical treatments for PHP, including exercise therapy, orthotics, corticosteroid injections, non-steroidal anti-inflammatory drugs, taping, manual therapy approaches and platelet rich plasma injections [14-16]. Electrotherapy approaches are also common and include ultrasound, low level laser therapy and extracorporeal shockwave therapy (ESWT) $[17,18]$. Of all currently available treatments, ESWT and exercise approaches appear to have the best evidence of long-term effectiveness [19]. Traditionally, plantar fascia specific stretching has been the most evidence-based exercise approach for PHP [20], however in recent years heavy slow resistance training has been shown to be a more effective form of exercise [21]. Other forms of exercise with inconclusive evidence of effectiveness for PHP include isometric exercise [22], intrinsic foot muscle strengthening [23] and kinetic chain strengthening targeting the hip musculature [24].

After first being successfully implemented in urology as a treatment to disintegrate renal calculi, ESWT is now applied to a range of musculoskeletal disorders such as 
tendinopathies [25]. For several decades, a significant evidence-base of effectiveness for ESWT has been increasing, particularly for lower limb tendinopathies and PHP [26]. Recalcitrant heel pain that is unresponsive to conservative physiotherapy such as exercise approaches, for three to six months are considered appropriate candidates for ESWT treatment [27]. Several systematic reviews and meta-analyses have concluded there is long-term safety and effectiveness of ESWT compared to placebo or other common PHP treatments, with its use consistently recommended in the literature for PHP [28-32]. In addition, recent evidence suggests that ESWT combined with exercise may be a more effective PHP treatment compared with either of the treatments in isolation [33]. Shockwaves generated by ESWT devices are considered mechanical acoustic energy waves which rapidly create high pressures [34]. This positive high pressure is quickly followed by negative pressure, which returns to ambient values within microseconds [35]. The high pressures generated from shockwaves induce cavitation within human tissue, which involves rapid formation, expansion and forceful collapse of vapor bubbles in liquids due to rapid pressure changes [36]. This cavitation process may stimulate a myriad of biological responses that can activate tissue regeneration effects such as stimulating neovascularisation and collagen synthesis in pathological musculoskeletal tissues [37].

In clinical practice, ESWT is rarely used as monotherapy and is more often combined with exercise, with there being a need for a comparison of polytherapy treatment approaches in future studies [38, 39]. Current research recommends that combined rather than isolated treatments be used in PHP treatment, with ESWT or exercise in isolation having inadequate long-term outcomes [13, 40, 41]. Despite this increasing evidence for ESWT and exercise in PHP treatment, optimal treatment protocols and clinical recommendations are lacking [42]. There is also a dearth of studies investigating a combined approach with a distinct lack of clinical recommendations on combined protocols, despite indications of combined treatment being more optimal than isolated treatments [43]. A search in PROSPERO, The Cochrane Library and in PubMed was performed and identified no systematic reviews comparing the effectiveness of combined ESWT and any type of exercise including stretching or resistance training versus other common treatment methods for PHP. Therefore, the aim of this work is to conduct such a 
systematic review to synthesise the available evidence and inform clinical recommendations regarding the combination of ESWT and exercise interventions for treating PHP. This systematic review was conducted in accordance with an a priori protocol, which has been registered in the PROSPERO database (CRD42020213286) [44].

\section{Review question}

The specific review question is: What is the effectiveness of combined extracorporeal shockwave therapy (ESWT) and exercise interventions compared with other treatments in treating plantar heel pain based on pain and function?

\section{Inclusion Criteria}

\section{Participants}

This review considered studies with adult participants aged 18 years old or over, formally diagnosed with PHP. Studies using local anaesthesia were excluded as research has demonstrated that it can diminish ESWT effectiveness [28]. Studies in which participants have the following ESWT contraindications were also excluded: diabetes mellitus, systematic inflammatory disease, previous foot surgery or fractures, malignancy, neurological disorders or pregnancy [45].

\section{Interventions}

This review included studies that have investigated the effectiveness of a combined intervention of any type of ESWT and any type of exercise in the treatment of PHP. Exercise types considered included cardiovascular exercise, stretching, strengthening, heavy slow resistance training, plyometric, or combined 
exercise interventions. Any healthcare setting including physiotherapy or podiatry clinics and departments, outpatient departments, primary care settings, specialist orthopaedic or surgical clinics, and rehabilitation clinics were considered.

\section{Comparators}

The following comprehensive list of common treatment methods were considered as comparators to combined ESWT and exercise:

1. Self-management, education and advice

2. Corticosteroid injection or topical corticosteroid

3. Stem-cell injection therapies

4. Blood derived injection therapies - platelet-rich-plasma or autologous conditioned plasma

5. Radial or focused ESWT (not combined with exercise)

6. Exercise intervention: including any type of single exercise (cardiovascular, stretching, strengthening, plyometric, heavy slow resistance training) or combined exercise approach (not combined with ESWT)

7. Standard/usual care or physiotherapy

8. Ultrasound

9. Low level laser therapy (LLLT) or photo-biomodulation therapy

10. Dry needling

11. Acupuncture

12. Manual/manipulative therapy or massage

13. Custom or standard orthotics, insoles or heel cups

14. Botulinum toxin type $A$ injection

15. Taping, bracing, or splinting

16. Surgery, including endoscopic plantar fasciotomy, open plantar fascia release or radiofrequency ablation

17. Combinations of two or more of treatments 1-16

18. Combined ESWT and exercise further combined with one or more of treatments $1-16$. 


\section{Outcomes}

Primary outcomes included heel pain and foot function. Heel pain evaluated by any validated scale such as the Visual Analogue Scale (VAS), Numeric Rating Scale (NRS), verbal rating scales or Foot Function Index pain subscale (FFI-PS) were considered $[46,47]$. Foot function evaluated by any validated scale for PHP such as the Foot Function Index (FFI) or Foot and Ankle Ability Measure (FAAM) were considered as function measures $[48,49]$. Additional secondary outcomes that were considered for inclusion if available included quality of life measures using validated scales such as the EQ-5D-5L [50].

\section{Types of studies}

The review was restricted to randomized controlled trials (RCTs) in which combined ESWT and exercise formed one arm of the trial. Trials with two or more arms were considered for inclusion. The use of active co-interventions such as pain medication (NSAIDs), education, orthotics and exercise were acceptable if used in all trial arms, to limit confounding [51]. In the hierarchy of evidence, systematic reviews of RCTs offer the highest level of evidence [52]. The strongest inferences can be drawn if the review is well conducted and includes methodologically sound RCTs with consistent results [53]. The authors preliminary work had identified several potentially eligible RCTs. Therefore, due to the availability of RCTs on this topic, they were chosen for inclusion over less robust study designs. Any deviation from the standard RCT design such as crossover or cluster designed trials were also permitted.

\section{Methods}

This systematic review followed the Preferred Reporting Items for Systematic Reviews and Meta-Analyses (PRISMA) guidelines [44] and was conducted in 
accordance with an a priori protocol, which was registered in the PROSPERO database (CRD42020213286).

\section{Search strategy}

The search strategy sought to identify published and unpublished trials utilizing a three-step search strategy. An initial scoping search of Medline was conducted (Appendix 1), followed by analysis of text words contained in the title and abstract and article index terms. A comprehensive systematic search using all identified keywords and index terms was conducted using the following databases: Medline, CINAHL, AMED, and SPORTDiscus. The search for unpublished studies included EThOS Networked Digital Library of Theses and Dissertations and the NICE Guidelines ESWT recommendations. The trial registers to searched included: ClinicalTrials.gov, UK clinical trials gateway, EU trials registry. Finally, in addition to the comprehensive search, supplementary searches were undertaken by reviewing bibliographies of articles selected for critical appraisal and related systematic reviews to find those not initially identified. The search strategy was adapted to each database and was limited to the year 2000 onwards. The year 2000 was chosen to ensure seminal work was not missed as research on ESWT for PHP first began around this time. Studies published in a language other than English were only considered if a translation was available as translation services are not available to the authors.

\section{Study selection}

All identified citations from the systematic search were uploaded into RefWorks (Proquest LLC), with duplicates removed. Two reviewers independently screened the titles and abstracts of all studies obtained against the identified inclusion criteria. Full-text versions of eligible studies were accessed and reviewed against the inclusion criteria. Studies were removed from the screening process if the information provided did not meet the criteria. The details of studies meeting the criteria were imported in to Covidence [44]. 


\section{Assessment of methodological quality}

Included studies were critically appraised by two independent reviewers at study level for methodological quality in the review using the standardized Cochrane risk of bias tool on Covidence [54]. Any disagreements that arose between the reviewers were resolved through discussion or with a third reviewer. The results of critical appraisal are reported in narrative form, and in a graph. All studies meeting the inclusion criteria, regardless of their methodological quality, underwent data extraction and synthesis and were included in the review. Seven criteria were appraised for RCTs. Item three which pertained to blinding was included but not considered highly relevant in final scoring and grading of recommendations, given that interventions could not be blinded. Therefore, a maximum high-quality score of 6 or 7 could be achieved, with all included studies scoring at least $4 / 7$, which was considered a moderate quality score (figure 2 ).

\section{Data extraction}

Data was extracted from studies included in the review using the standardised data extraction tool available on Covidence by two independent reviewers [44]. The data extracted included specific details relative to the interventions, comparators, populations, study methods and outcomes of significance to the review question which include heel pain and foot function. Any disagreements between the reviewers were resolved through discussion or with a third reviewer.

\section{Data synthesis}

Statistical pooling and meta-analysis were not possible due to clinical and methodological heterogeneity; therefore, findings are presented in narrative synthesis. Although some studies used the same outcome measures, no studies used the exact same clinical intervention protocol or comparator with wide variances in intervention protocols, outcome measures and follow-up times. 


\section{Assessing certainty of findings and quality of evidence}

A summary of findings table was created following The Grading of Recommendations, Assessment, Development and Evaluation (GRADE) approach for assessing the quality of evidence [55]. Evidence from RCTs starts at high quality and the certainty is increased or decreased for several reasons, such as risk of bias [56]. The outcomes reported in the summary of findings table include heel pain and foot function for the interventions. For each outcome, a ranking of 'high', 'moderate', 'low' or 'very low' was assigned to the quality of evidence based on the risk of bias. There is by necessity a considerable amount of subjectivity in each decision as GRADE cannot be implemented mechanically. However, GRADE does provide a reproducible and transparent framework for grading certainty in evidence [57].

\section{Results}

\section{Search results and study inclusion}

The initial search strategy identified a total of 405 references, which was reduced to 20 studies obtained in full text after screening and removal of duplicates (Figure 1). Reasons for excluding studies obtained in full text included wrong study design such as not being RCTs (three studies), duplication of results (two studies), wrong intervention (two studies), and wrong outcomes (one study). The remaining 12 RCTs underwent quality appraisal and were included in the review.

\section{Methodological quality}

Item 3 from the Cochrane risk of bias tool which pertains to blinding was considered not highly relevant as blinding is not possible for ESWT and exercise interventions, therefore the highest RCT score was considered as six or seven, with seven studies achieving this score [33, 40,42, 58-61]. Three studies scored 
five [62-64] and the remaining two scored four $[65,66]$. These five studies were unclear about randomization methods and if concealed allocation to treatment groups was used. Two studies did not disclose if outcome assessors were blind to group assignment $[65,66]$.

\section{Characteristics of included studies}

The 12 included RCTs (Table 1 ) were conducted in a range of countries: Turkey (four), Iran (two), Egypt, Brazil, Germany, Singapore, Canada and Spain. All included studies were conducted within a healthcare setting and there was a total of 861 participants. All participants were diagnosed with PHP, however, there were wide variances in the duration of the condition, ranging from one month [42] to 12 months [33]. All studies investigated the effects of the interventions on heel pain, with ten using VAS scales. The studies also investigated foot function using a variety of outcome measures. Four studies used the full FFI $[59,62,64,66]$ and three used the FFI-PS [33, 40, 42]. No studies used the FAAM or assessed the effects of the interventions on quality of life or used a global rating of change (GRoC) score. The only exercise intervention used in the studies were stretching interventions, with all studies using combined PFSS and gastrocnemius stretching, with only one study not using gastrocnemius stretching and only PFSS [33]. This is despite evidence showing that PFSS is superior to gastrocnemius stretching [20]. No studies used any other type of exercise such as strengthening exercises or resistance training approaches, despite heavy slow resistance training been found to be a more effective exercise treatment than stretching for treating PHP [21]. The studies used a variety of comparator interventions, with some having three or four trial arms comparing multiple combined interventions. 
Figure 1: PRISMA study flow diagram
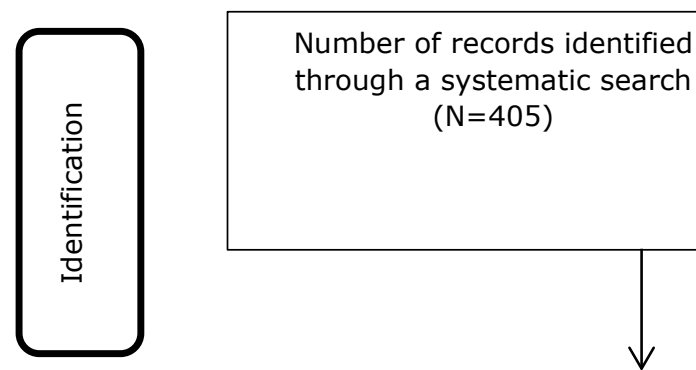
through a systematic search $(N=405)$
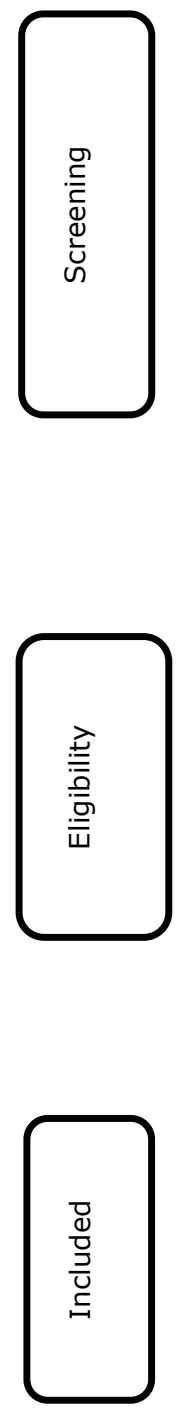

Number of additional records identified through other sources $(N=0)$

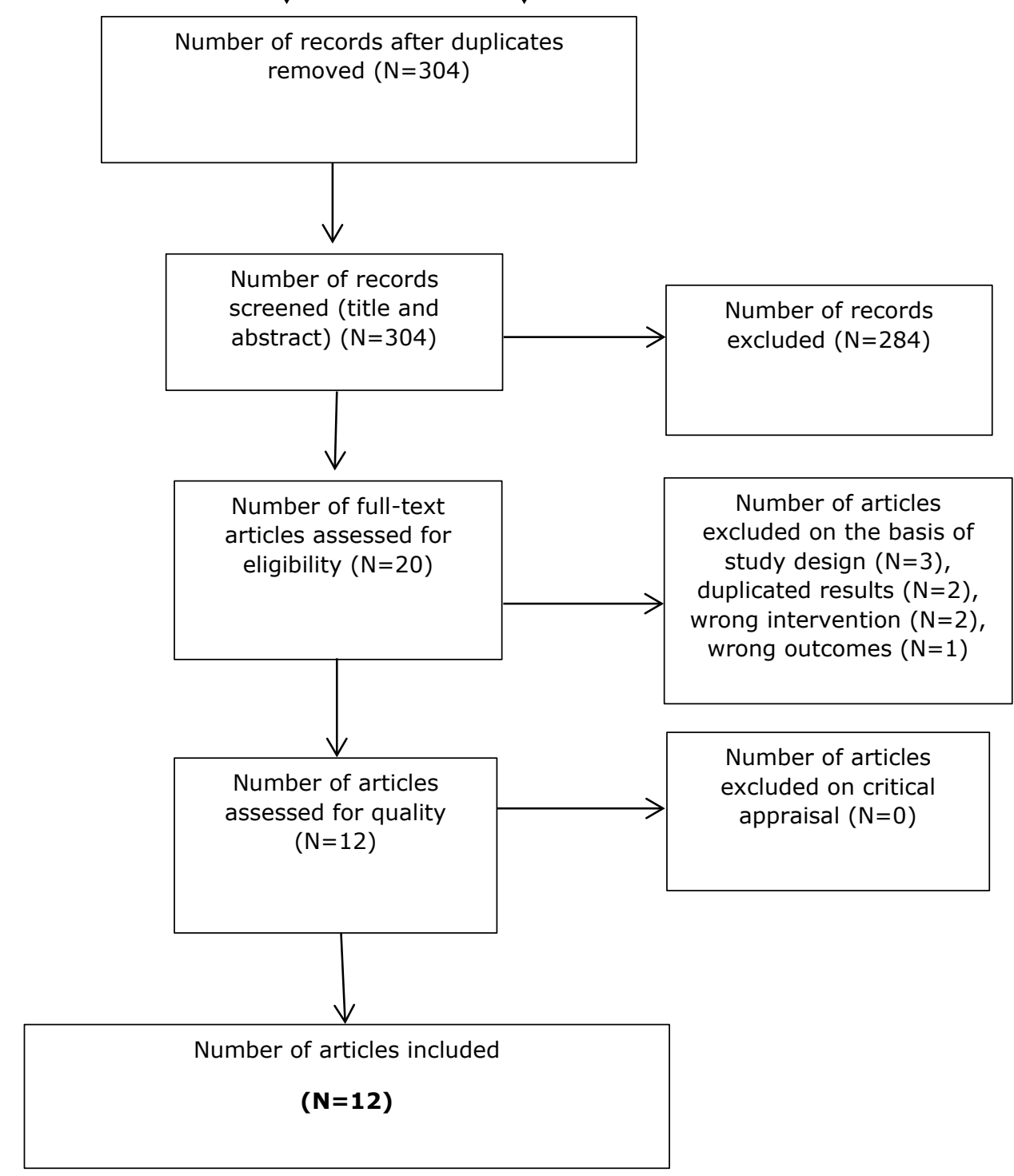

From: Moher D, Liberati A, Tetzlaff J, Altman DG, The PRISMA Group (2009). Preferred Reporting Items for Systematic Reviews and Meta-Analyses: The PRISMA Statement. PLoS Med 6(6): e1000097. doi:10.1371/journal.pmed100009 
Figure 2: Risk of bias summary

\begin{tabular}{|c|c|c|c|c|c|c|c|c|}
\hline & & & & & & & & \\
\hline & D1 & D2 & D3 & D4 & D5 & D6 & D7 & Overall \\
\hline Okur et al. 2019 & & & & & & & & \\
\hline Bagcier et al. 2020 & & & & & & & & \\
\hline Grecco et al. 2013 & & & & & & & & \\
\hline Akinoglu et al. 2013 & & & & & & & & \\
\hline Cinar et al. 2018 & & & & & & & & \\
\hline Rompe et al. 2015 & & & & & & & & \\
\hline Ulusoy et al. 2017 & & & & & & & & \\
\hline Roca et al. 2016 & & & & & & & & \\
\hline Eslamian et al. 2016 & & & & & & & & \\
\hline Chew et al. 2013 & & & & & & & & \\
\hline Vahdatpour et al. 201 & & & & & & & & \\
\hline Takla et al. 2019 & & & & & & & & \\
\hline & 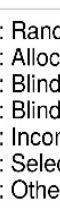 & & & & & & & $\begin{array}{l}\text { Judgement } \\
\text { ( High } \\
- \text { Unclear } \\
\text { + Low }\end{array}$ \\
\hline
\end{tabular}




\section{Figure 3: Risk of bias graph}

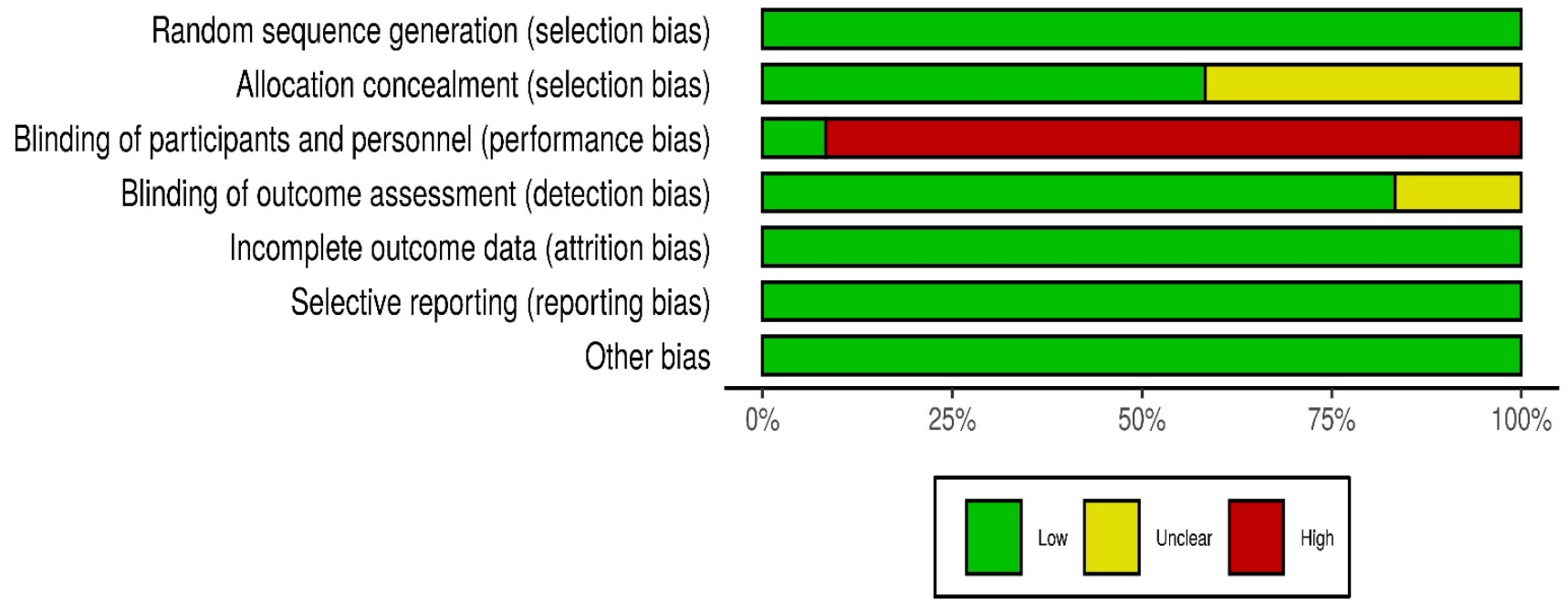

\section{Findings}

The findings are presented in relation to the primary outcomes of heel pain and foot function from combined ESWT and stretching (PFSS and gastrocnemius) interventions versus other interventions.

\section{Stretching exercise alone}

Four studies contained a comparator group involving stretching exercise alone $[40,42,58,66]$. Chew et al. [58] found clinically and statistically significant VAS pain improvement with combined ESWT and stretching versus stretching at month one $(-2$ points $\vee-0.75, P=.017)$, three $(-3.25$ points $\vee 1.0, P=.022)$ and $\operatorname{six}(-$ 5.5 points $\vee 3.0, P=.042$ ). Akinoglu et al. [66] found clinically and statistically significant improvement in FFI in the combined group compared to stretching only $(P<0.05)$. Takla et al. [40] found the combined group was clinically and statistically superior to the stretching only group measured by VAS ( 7.8 to $1.7=$ $48.48 \%$ decrease $\vee 7.8$ to $8.1=3.8 \%$ increase) and FFI scores ( 41.8 to $28.9=$ 
$30.8 \%$ decrease $v 43.8$ to $43.5=0.6 \%$ increase $)$ at 12 weeks $(P=0.0001)$. Only, Cinar et al. [42] found the combined group not to be superior for reducing pain at 3 weeks, but it was statistically significantly superior at 3 months $(P=.035)$. Patients having clinically meaningful FFI-PS improvements were also higher for ESWT (61\% v 50\%).

\section{ESWT alone}

One study compared combined ESWT and PFSS without gastrocnemius stretching with ESWT alone [33]. Two months after baseline, FFI-PS score was clinically and statistically significantly improved for the combined group (-20.1 V -12.2 points) compared with ESWT alone $(P=<0.001)$. Statistically significant but not clinically important differences remained at four and 24 months $(P=<0.01)$.

\section{Ultrasound combined with stretching}

Three studies compared combined ESWT and stretching with ultrasound and stretching $[63,65,66]$. Akinoglu et al. [66] found that although both groups had improved FFI-PS scores, the improvements were more clinically meaningful (28.25 $V 43.28)$ in the ultrasound group at one month, which was statistically significant $(P=<0.05)$. Grecco et al. [65] found clinically meaningful but no statistically significant differences between the groups for VAS pain at three $(65 \% \mathrm{v} 70 \% \mathrm{good}$ outcome) and 12 months ( $85 \%$ v $80 \%$ good outcome), with good outcome defined as VAS score of $1 / 10$ or less. Ulusoy et al. [63] found ESWT and stretching statistically and clinically significantly superior after one month (success defined as $60 \%$ or more VAS improvement) to ultrasound and stretching ( $65 \% \mathrm{~V} 23.5 \%$ ) for pain measured with VAS $(P=0.12)$. 


\section{Autologous conditioned plasma (ACP) injection combined with stretching}

One study used a single ACP injection combined with stretching [58]. At month one, three and six, both ACP $(-2.0,-3.0,-5.0)$ and $\operatorname{ESWT}(-2.0,-3.25,-5.5)$ combined with stretching was found to be superior to stretching only $(-0.75,-1.0$, -3.0) in VAS score. These differences were statistically significant at each timepoint for both ESWT $(P=.017, .022, .042)$ and ACP $(P=.037, .053, .080)$ versus stretching alone. There was no significant difference at each time-point between ACP and ESWT and stretching in VAS scores $(P=.575, .947, .791)$.

\section{Single corticosteroid injection combined with stretching}

One study found that ESWT and stretching had better scores in VAS and FFI compared to corticosteroid injection and stretching [62]. Although these changes were clinically meaningful, they were not statistically significant [FFI decreased to 19.65 from 60.25 points (67.4\% improvement) in ESWT vs 31.50 from 60.25 points (47.7\% improvement) in injection group at week $8,(P=0.072)]$. Good or excellent results in the opinions of patients were achieved in 55\% of ESWT and $30 \%$ of corticosteroid injection groups $(P=0.11)$.

\section{Botulinum toxin type A injection combined with stretching}

One study compared one session of ESWT with one injection of botulinum toxin type-A (BoNT-A), both combined with stretching [61]. In the ESWT group, the median (and interquartile range) of improvement in the VAS pain, when taking the first steps, was $2(1-4)$ points, and in the BoNT-A group the same result was

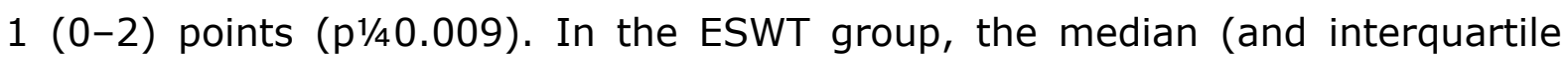
range) of improvement in the Roles and Maudsley scale was 1 (0-1) points, and in the group of patients that received BoNT-A the same result was $0(0-1)$ points $\left(p^{1 / 40.006)}\right.$. In a multivariate analysis use of ESWT was associated with 
improvement of pain and function. The combined ESWT and stretching treatment was found superior to BoNT-A.

\section{Custom fabricated orthotics (CFO) combined with stretching}

One study compared ESWT versus CFO, with both combined with stretching [59]. Both groups achieved significant clinically important improvements in VAS and FFI scores at 4, 12, 24 and 48 weeks compared with their baseline values. CFO VAS scores over the five time-points $(6.6,5.2,4.4,3.9,4.1)$ and FFI $(82.5,63.9,59.3$, $55.2,51.8)$ were slightly better than ESWT VAS scores $(6.3,5.1,4.6,4.4,4.8)$ and FFI $(78.3,65.2,62.8,62.4,66.4)$. However, there was no statistically significant difference between treatments and neither method was superior $(P<$ $0.001)$.

\section{Low level laser therapy (LLLT) combined with stretching}

Three studies compared ESWT and stretching with LLLT and [40, 42, 63]. Ulusoy et al. [63] found that although LLLT had a higher clinically meaningful success rate than ESWT for pain and function $(70.6 \% \vee 65 \%)$ there was no statistically significant difference between the groups $(P=.717)$ in VAS scores. Takla et al. [40] found that although both groups had statistically significant and clinically meaningful improvements in VAS and FFI scores, ESWT and stretching was significantly superior $(P<0.0001)$. Cinar et al. [42] found that LLLT had statistically significant lower FFI-PS compared to ESWT and stretching at three months $(P=.003)$. Patients having clinically meaningful FFI-PS improvements were also higher for LLLT than ESWT (79\% V 61\%). 


\section{ESWT and stretching combined with dry needling}

One study investigated the additive effect of dry needling to three sessions of ESWT combined with stretching [64]. In both groups, there were statistically significant improvements in VAS pain, and FFI scores $(p \leq .001)$. In intergroup comparison, it was found that VAS scores, and FFI pain subscale scores $(p=.034)$ were statistically superior in the combined dry needling group. There was no statistically significant difference between the groups in FFI disability $(p=.081)$, and FFI activity limitation subscale $(p=.226)$ scores. ESWT, stretching and dry needling combination therapy was superior for pain improvement.

\section{ESWT and stretching combined with topical corticosteroid}

One study investigated the additive effect of topical corticosteroid to ESWT and stretching [60]. At one month, VAS pain showed statistically significant improvement in the intervention group, but not at three months $(P=0.006)$. $A$ $50 \%$ improvement in VAS scores was considered clinically successful, with $75 \%$ (versus $45 \%$ ) of patients in the intervention group achieving this at one month and $80 \%$ (versus $65 \%$ ) at three months $(P=0.135)$.

\section{ESWT and stretching combined with Photobiomodulation therapy (PBMT)}

Both ESWT and PBMT (equivalent to LLLT) combined with stretching were effective in decreasing pain and improving function measured by VAS, and FFI scores compared to stretching and sham PBMT [40]. However, application of PBMT with ESWT and stretching was clinically superior over ESWT and PBMT with stretching alone, in VAS and FFI scores, which was statistically significant $(P<0.0001)$. The study calculated overall VAS and FFI effect sizes of 85.452 ( 0.68 effect size), and 49.76 ( 0.56 effect size) for the combined interventions. 
Table 1: Characteristics of included studies

\begin{tabular}{|c|c|c|c|c|c|}
\hline $\begin{array}{l}\text { Study/ } \\
\text { Country }\end{array}$ & $\begin{array}{l}\text { Setting/ } \\
\text { context }\end{array}$ & $\begin{array}{l}\text { Participant } \\
\text { characterist } \\
\text { ics }\end{array}$ & Groups & $\begin{array}{l}\text { Outcomes } \\
\text { measured }\end{array}$ & Description of main results \\
\hline
\end{tabular}




\begin{tabular}{|c|c|c|c|c|c|}
\hline & & $\begin{array}{l}\text { radiographs } \\
\text { of the foot, } \\
\text { and unilateral } \\
\text { PF. }\end{array}$ & $\begin{array}{l}\text { stretching) twice a day } \\
\text { for four weeks }(n=18)\end{array}$ & & \\
\hline
\end{tabular}




\begin{tabular}{|c|c|c|c|c|c|}
\hline & & & & & $\begin{array}{l}\text { ESWT plus conventional } \\
\text { treatments resulted in improved } \\
\text { pain and functional outcomes } \\
\text { compared with conventional } \\
\text { treatment alone. There was no } \\
\text { significant difference between ACP } \\
\text { and ESWT in terms of VAS and } \\
\text { AOFAS ankle-hindfoot scale } \\
\text { improvements, although the ACP } \\
\text { group demonstrated greater } \\
\text { reductions in plantar fascia } \\
\text { thickness. }\end{array}$ \\
\hline $\begin{array}{l}\text { CINAR E et } \\
\text { al. } 2018 . \\
{[42]} \\
\text { Canada }\end{array}$ & $\begin{array}{l}\text { Outpatient } \\
\text { physiotherap } \\
\text { y department } \\
\text { at a multi- } \\
\text { centre public } \\
\text { hospital. }\end{array}$ & $\begin{array}{l}\text { Adults } 18 \\
\text { years or older } \\
\text { diagnosed } \\
\text { with plantar } \\
\text { fasciitis for } \\
\text { one month or } \\
\text { longer. }\end{array}$ & $\begin{array}{l}\text { 1. Radial shockwave } \\
\text { therapy (ESWT), once } \\
\text { weekly for } 3 \text { weeks \& } \\
\text { Full-length silicone } \\
\text { insoles ( } 3 \text { months) \& } \\
\text { Home exercise } \\
\text { including } \\
\text { gastrocnemius and } \\
\text { plantar fascia } \\
\text { stretching ( } 3 \text { weeks) } \\
\text { ( } \mathrm{n}=25 \text { ). } \\
2 . \text { Laser therapy } \\
\text { (LLLT), three times a } \\
\text { week for ten sessions } \\
\text { in total \& Full-length } \\
\text { silicone insoles ( } 3 \\
\text { months) \& Home } \\
\text { exercise including }\end{array}$ & $\begin{array}{l}\text { Foot Pain } \\
\text { measured by the } \\
\text { Foot Function } \\
\text { Index pain } \\
\text { subscale (FFI-p). } \\
\text { Functional pain } \\
\text { was measured } \\
\text { through 12- } \\
\text { minute walking } \\
\text { test and Numeric } \\
\text { Rating Scale for } \\
\text { Pain (NRS-p). } \\
\text { The scores were } \\
\text { recorded at } \\
\text { baseline, third } \\
\text { week, and third } \\
\text { month after the } \\
\text { treatment. }\end{array}$ & $\begin{array}{l}\text { There was a significant } \\
\text { improvement in pain over the } 3 \\
\text { months in all groups on both FFI- } p \\
(P<.001) \text { and NRS- } p(P<.001) \text {. } \\
\text { In NRS- } p \text {, LLLT group had } \\
\text { significantly lower pain than ESWT } \\
(P=.002) \text { at the third week and } \\
\text { control }(P=.043 \text { ) and ESWT ( } P= \\
.003) \text { at third month. In FFI- } p \\
\text { total score, ESWT group had } \\
\text { higher pain than LLLT ( } P=.003) \\
\text { and control ( } P=.035) \text { groups at } \\
\text { third week and LLLT ( } P=.010) \\
\text { group at third month. When LLLT } \\
\text { and ESWT were combined with } \\
\text { usual care, LLLT was found to be } \\
\text { more effective than ESWT in }\end{array}$ \\
\hline
\end{tabular}




\begin{tabular}{|c|c|c|c|c|c|}
\hline & & & $\begin{array}{l}\text { gastrocnemius and } \\
\text { plantar fascia } \\
\text { stretching ( } 3 \text { weeks) } \\
(n=24) \text {. } \\
\text { 3. Control group: Full } \\
\text { length silicone insoles } \\
\text { ( } 3 \text { months) \& Home } \\
\text { exercise including } \\
\text { gastrocnemius and } \\
\text { plantar fascia } \\
\text { stretching ( } 3 \text { weeks) } \\
(n=17) .\end{array}$ & $\begin{array}{l}\text { Analysis was } \\
\text { performed using } \\
\text { repeated } \\
\text { measures } \\
\text { ANOVA. }\end{array}$ & $\begin{array}{l}\text { reducing pain in PF at short-term } \\
\text { follow-up. }\end{array}$ \\
\hline $\begin{array}{l}\text { VAHDATPOUR } \\
\text { B et al. } 2018 . \\
\text { [60] } \\
\text { Iran }\end{array}$ & $\begin{array}{l}\text { Physical } \\
\text { medicine and } \\
\text { rehabilitation } \\
\text { clinic based in } \\
\text { a hospital }\end{array}$ & $\begin{array}{l}\text { Criteria for } \\
\text { inclusion } \\
\text { were patients } \\
\text { older than } 18 \\
\text { years with } \\
\text { chronic } \\
\text { recalcitrant } \\
\text { plantar } \\
\text { fasciitis } \\
\text { (lasting at } \\
\text { least } 6 \\
\text { months and } \\
\text { refractory to } \\
\text { conservative } \\
\text { treatment). } \\
\text { Only patients } \\
\text { with Roles } \\
\text { and Maudsley }\end{array}$ & $\begin{array}{l}\text { 1. Four sessions at } \\
\text { weekly intervals of } \\
\text { ESWT combined with } \\
\text { topical corticosteroid } \\
\text { and home exercise } \\
\text { including } \\
\text { gastrocnemius and } \\
\text { plantar fascia } \\
\text { stretching }(n=40) \\
2 . \text { Four sessions at } \\
\text { weekly intervals of } \\
\text { ESWT combined with } \\
\text { topical Vaseline } \\
\text { (control) and home } \\
\text { exercise including } \\
\text { gastrocnemius and } \\
\text { plantar fascia } \\
\text { stretching }(n=40)\end{array}$ & $\begin{array}{l}\text { Pain severity } \\
\text { was assessed } \\
\text { using visual } \\
\text { analogue scale } \\
\text { (VAS) at } \\
\text { baseline and } 1 \\
\text { and } 3 \text { months } \\
\text { after VAS score } \\
\text { recorded as } \\
\text { follows: } \bullet \text { Heel } \\
\text { pain while taking } \\
\text { the first steps in } \\
\text { the morning } \\
\text { (VAS morning) } \\
\text { Heel pain while } \\
\text { doing a daily } \\
\text { activity (VAS } \\
\text { daily). Activity }\end{array}$ & $\begin{array}{l}\text { One month after intervention, VAS } \\
\text { morning showed significant } \\
\text { improvement in intervention group } \\
(P=0.006) \text { and RMS showed } \\
\text { better improvement in } \\
\text { intervention group ( } P=0.026) \text {. } \\
\text { There was no significant difference } \\
\text { between the two groups after } 3 \\
\text { months in RMS or VAS score. PF } \\
\text { thickness was decreased } \\
\text { significantly in both groups, but it } \\
\text { was not significant between the } \\
\text { two groups ( } P=0.292) \text {. This } \\
\text { combinational therapy yielded } \\
\text { earlier pain reduction and } \\
\text { functional improvement than using } \\
\text { shock wave alone and topical } \\
\text { corticosteroid could enhance the }\end{array}$ \\
\hline
\end{tabular}




\begin{tabular}{|c|c|c|c|c|c|}
\hline & & $\begin{array}{l}\text { score (RMS) } \\
\text { of } 4 \text { and PF } \\
\text { thickness of } \\
>4 \mathrm{~mm} \text { with } \\
\text { ultrasonograp } \\
\text { hy were } \\
\text { enrolled in } \\
\text { this study. }\end{array}$ & & $\begin{array}{l}\text { limitation due to } \\
\text { pain was } \\
\text { assessed with } \\
\text { the modified } \\
\text { RMS } 1 \text { and } 3 \\
\text { months after } \\
\text { intervention. }\end{array}$ & $\begin{array}{l}\text { effectiveness of shockwave in } \\
\text { short-term in the treatment of } \\
\text { recalcitrant plantar fasciitis. }\end{array}$ \\
\hline
\end{tabular}




\begin{tabular}{|c|c|c|c|c|c|}
\hline & & & $\begin{array}{l}\text { weeks) and daily } \\
\text { home exercise } \\
\text { including } \\
\text { gastrocnemius and } \\
\text { plantar fascia } \\
\text { stretching for three } \\
\text { weeks ( } n=30 \text { ) } \\
4 \text {. Sham-PBMT and } \\
\text { daily home exercise } \\
\text { including } \\
\text { gastrocnemius and } \\
\text { plantar fascia } \\
\text { stretching for three } \\
\text { weeks ( } n=30 \text { ) }\end{array}$ & $\begin{array}{l}\text { final treatment } \\
\text { session. }\end{array}$ & $\begin{array}{l}\text { alone, and ESWT was superior } \\
\text { over PBMT in terms of reducing } \\
\text { pain sensitivity and increasing } \\
\text { function. }\end{array}$ \\
\hline $\begin{array}{l}\text { GRECCO MV } \\
\text { et al. } 2013 . \\
{[65]} \\
\text { Brazil }\end{array}$ & $\begin{array}{l}\text { Institute of } \\
\text { Orthopaedics } \\
\text { and } \\
\text { Traumatology } \\
\text { University } \\
\text { hospital }\end{array}$ & $\begin{array}{l}\text { Adults ages } \\
20 \text { years or } \\
\text { older } \\
\text { diagnosed } \\
\text { with plantar } \\
\text { fasciitis for } 3 \\
\text { months or } \\
\text { longer, with } \\
\text { plantar fascia } \\
\text { thickness } \\
\text { greater than } \\
4 \text { mm, as } \\
\text { assessed } \\
\text { using } \\
\text { ultrasonograp } \\
\text { hy. The mean }\end{array}$ & $\begin{array}{l}\text { 1. Conventional } \\
\text { physiotherapy: } \\
\text { Ultrasound } x \text { ten } \\
\text { sessions with home } \\
\text { exercise program } \\
\text { including plantar fascia } \\
\text { and gastrocnemius } \\
\text { stretching }(n=20) \\
\text { 2. Radial ESWT x } 3 \\
\text { sessions at weekly } \\
\text { intervals, plantar } \\
\text { fascia and } \\
\text { gastrocnemius } \\
\text { stretching }(n=20)\end{array}$ & $\begin{array}{l}\text { Visual analogue } \\
\text { scale (VAS) for } \\
\text { morning pain, } \\
\text { gait and } \\
\text { standing } \\
\text { upright; - } \\
\text { Fischer's } \\
\text { algometer to } \\
\text { quantify the } \\
\text { painful pressure } \\
\text { at the insertion } \\
\text { of the plantar } \\
\text { fascia in the } \\
\text { calcaneus and } \\
\text { the middle third } \\
\text { of the medial }\end{array}$ & $\begin{array}{l}\text { At the } 12 \text {-month follow-up, both } \\
\text { treatments were effective for } \\
\text { improving pain and functional } \\
\text { ability among the patients with } \\
\text { plantar fasciitis. The improvement } \\
\text { with shockwaves was faster. }\end{array}$ \\
\hline
\end{tabular}




\begin{tabular}{|c|c|c|c|c|c|}
\hline & & $\begin{array}{l}\text { age was } \\
49.6 \text { i11.8 } \\
\text { years (range: } \\
25-68 \text { years), } \\
85 \% \text { were } \\
\text { female, } 88 \% \\
\text { were } \\
\text { overweight, } \\
63 \% \text { were } \\
\text { affected } \\
\text { bilaterally, } \\
\text { and } 83 \% \\
\text { used } \\
\text { analgesics } \\
\text { regularly. }\end{array}$ & & $\begin{array}{l}\text { gastrocnemius; } \\
\text { - Use of } \\
\text { analgesics } \\
\text { before and } \\
\text { during the } \\
\text { treatment. }\end{array}$ & \\
\hline
\end{tabular}




\begin{tabular}{|c|c|c|c|c|c|}
\hline & & & & & $\begin{array}{l}\text { achieved in } 55 \% \text { of ESWT and } \\
30 \% \text { of corticosteroid injection } \\
\text { groups }(P=0.11)\end{array}$ \\
\hline $\begin{array}{l}\text { ROMPE JD et } \\
\text { al. } 2015 . \\
\text { [33] } \\
\text { Germany }\end{array}$ & $\begin{array}{l}\text { Orthopaedic } \\
\text { hospital }\end{array}$ & $\begin{array}{l}\text { Adults aged } \\
18 \text { years or } \\
\text { older with } \\
\text { diagnosed } \\
\text { plantar } \\
\text { fasciopathy } \\
\text { for } 12 \\
\text { months or } \\
\text { longer in } \\
\text { duration. }\end{array}$ & $\begin{array}{l}\text { 1. Three sessions at } \\
\text { weekly intervals of } \\
\text { Shockwave therapy } \\
\text { (ESWT) and daily } \\
\text { Plantar fascia } \\
\text { stretching for } 8 \text { weeks } \\
\text { ( } n=79 \text { ) } \\
\text { 2. Three sessions at } \\
\text { weekly intervals of } \\
\text { Shockwave therapy } \\
\text { (ESWT) }(n=73)\end{array}$ & $\begin{array}{l}\text { Heel pain } \\
\text { measured by the } \\
\text { pain sub-scale of } \\
\text { the validated } \\
\text { Foot Function } \\
\text { Index (PS-FFI). } \\
\text { Patient-relevant } \\
\text { outcome } \\
\text { measures } \\
\text { (SROM) } \\
\text { questionnaire. }\end{array}$ & $\begin{array}{l}\text { At two months after baseline, the } \\
\text { Foot Function Index sum score } \\
\text { showed significantly greater } \\
\text { changes for the patients managed } \\
\text { with shock-wave therapy plus } \\
\text { plantar fascia-specific stretching } \\
\text { than those managed with shock- } \\
\text { wave therapy alone }(P<0.001) \text {, } \\
\text { as well as individually for item } 2 \text { ( } P \\
<0.001) \text {. Twenty-four patients in } \\
\text { Group } 1 \text { ( } 32 \% \text { ) versus forty-seven } \\
\text { patients in Group } 2(59 \%) \text { were } \\
\text { satisfied with the treatment ( }<< \\
0.001) \text {. Significant differences } \\
\text { persisted at four months, but not } \\
\text { at twenty-four months. }\end{array}$ \\
\hline $\begin{array}{l}\text { ULUSOY A et } \\
\text { al. } 2017 . \\
\text { [63] } \\
\text { Turkey }\end{array}$ & $\begin{array}{l}\text { University } \\
\text { physical } \\
\text { medicine and } \\
\text { rehabilitation } \\
\text { department }\end{array}$ & $\begin{array}{l}\text { Adults } 18 \\
\text { years or older } \\
\text { diagnosed } \\
\text { with plantar } \\
\text { fasciitis of } 6 \\
\text { months or } \\
\text { longer in } \\
\text { duration that } \\
\text { was } \\
\text { unresponsive } \\
\text { to }\end{array}$ & $\begin{array}{l}\text { 1. } 5 \text { sessions per week } \\
\text { for } 3 \text { weeks ( } 15 \\
\text { sessions) of LLLT and } \\
\text { home exercise } \\
\text { including } \\
\text { gastrocnemius and } \\
\text { plantar fascia } \\
\text { stretching ( } n=20) \\
2.5 \text { sessions per week } \\
\text { for } 3 \text { weeks ( } 15 \\
\text { sessions) of }\end{array}$ & $\begin{array}{l}\text { All patients were } \\
\text { assessed using } \\
\text { the visual } \\
\text { analogue scale } \\
\text { (VAS), heel } \\
\text { tenderness index } \\
\text { (HTI), American } \\
\text { Orthopaedic Foot } \\
\text { and Ankle } \\
\text { Society (AOFAS) } \\
\text { ankle-hindfoot }\end{array}$ & $\begin{array}{l}\text { Significant improvement was } \\
\text { measured using the mean VAS, } \\
\text { AOFAS scale, and HTI scores for } \\
\text { all } 3 \text { groups. The thickness of the } \\
\text { plantar fascia had decreased } \\
\text { significantly on MRI in all } 3 \\
\text { groups. The treatment success } \\
\text { rate was } 70.6 \% \text { in the LLLT group, } \\
65 \% \text { in the ESWT group, and } \\
23.5 \% \text { in the US group. LLLT and } \\
\text { ESWT proved significantly superior }\end{array}$ \\
\hline
\end{tabular}




\begin{tabular}{|c|c|c|c|c|c|}
\hline & & $\begin{array}{l}\text { conservative } \\
\text { treatment. }\end{array}$ & $\begin{array}{l}\text { continuous ultrasound } \\
\text { (US) and home } \\
\text { exercise including } \\
\text { gastrocnemius and } \\
\text { plantar fascia } \\
\text { stretching ( } n=20) \\
\text { 3. Once weekly for } 3 \\
\text { weeks ( } 3 \text { sessions) of } \\
\text { ESWT and home } \\
\text { exercise including } \\
\text { gastrocnemius and } \\
\text { plantar fascia } \\
\text { stretching }(n=20)\end{array}$ & $\begin{array}{l}\text { scale, Roles- } \\
\text { Maudsley score, } \\
\text { and MRI before } \\
\text { and } 1 \text { month } \\
\text { after treatment. } \\
\text { The primary } \\
\text { efficacy success } \\
\text { criterion was the } \\
\text { percentage of } \\
\text { decrease in heel } \\
\text { pain of >60\% } \\
\text { from baseline at } \\
1 \text { month after } \\
\text { treatment for } 2 \\
\text { of the } 3 \text { pain } \\
\text { (VAS) } \\
\text { measurements. }\end{array}$ & $\begin{array}{l}\text { to US therapy using the primary } \\
\text { efficacy criterion ( } p=.006 \text { and } p \\
=.012 \text {, respectively), with no } \\
\text { significant difference between the } \\
\text { LLLT and ESWT groups ( } p>.05) \text {. } \\
\text { The treatment of chronic plantar } \\
\text { fasciitis with LLLT and ESWT } \\
\text { resulted in similar outcomes and } \\
\text { both were more successful than } \\
\text { US therapy in pain improvement } \\
\text { and functional outcomes. }\end{array}$ \\
\hline
\end{tabular}




\begin{tabular}{|c|c|c|c|c|c|}
\hline & & & $\begin{array}{l}\text { stretching for } 4 \text { weeks } \\
(n=43)\end{array}$ & $\begin{array}{l}\text { Status } \\
\text { Questionnaire } \\
\text { (FHSQ) was } \\
\text { used to evaluate } \\
\text { foot health. }\end{array}$ & $\begin{array}{l}\text { Neither method was superior in } \\
\text { treating plantar fasciitis. }\end{array}$ \\
\hline $\begin{array}{l}\text { BAGCIER F et } \\
\text { al. 2020. } \\
\text { [64] } \\
\text { Turkey }\end{array}$ & $\begin{array}{l}\text { Physical } \\
\text { medicine and } \\
\text { rehabilitation } \\
\text { outpatient } \\
\text { clinic }\end{array}$ & $\begin{array}{l}\text { Adults aged } \\
\text { between } 18 \\
\text { and } 70 \text { years, } \\
\text { having } \\
\text { symptoms at } \\
\text { least for } 6 \\
\text { weeks, } \\
\text { diagnosed } \\
\text { with plantar } \\
\text { fasciitis }\end{array}$ & $\begin{array}{l}\text { 1. Three sessions at } \\
\text { weekly intervals of } \\
\text { Shockwave therapy } \\
\text { (ESWT) followed by } \\
\text { cold application for } 15 \\
\text { minutes and home } \\
\text { Plantar fascia and } \\
\text { gastrocnemius } \\
\text { stretching ( } n=20) \text {, } \\
2 \text {. Three sessions at } \\
\text { weekly intervals of } \\
\text { Shockwave therapy } \\
\text { (ESWT) followed by } \\
\text { dry needling of } \\
\text { gastrocnemius muscle } \\
\text { and cold application } \\
\text { for } 15 \text { minutes and } \\
\text { home Plantar fascia } \\
\text { and gastrocnemius } \\
\text { stretching ( } n=20)\end{array}$ & $\begin{array}{l}\text { Pain (VAS), Pain } \\
\text { (FFI), Function } \\
\text { (FFI disability) }\end{array}$ & $\begin{array}{l}\text { In both groups, there were } \\
\text { statistically significant } \\
\text { improvements in VAS pain, and } \\
\text { FFI's pain, disability, and activity } \\
\text { limitation subscales scores ( } p \leq \\
.001) \text {. In intergroup comparison, it } \\
\text { was showed that VAS scores, } \\
\text { maximum painless standing time } \\
(p=.002), \text { maximum painless } \\
\text { walking distance ( } p \leq .001) \text {, and } \\
\text { FFI pain subscale scores ( } p= \\
.034) \text { were statistically superior in } \\
\text { the ESWT-DN group. There was } \\
\text { not statistically difference between } \\
\text { the groups in pressure pain } \\
\text { threshold ( } p=.132), \text { FFI disability } \\
\text { ( } p=.081), \text { and FFI activity } \\
\text { limitation subscale ( } p=.226) \\
\text { scores. ESWT and dry needling } \\
\text { combination therapy was superior } \\
\text { for pain scores. }\end{array}$ \\
\hline $\begin{array}{l}\text { ROCA B et al. } \\
2016 . \\
{[61]}\end{array}$ & $\begin{array}{l}\text { General } \\
\text { hospital }\end{array}$ & $\begin{array}{l}\text { Adults older } \\
\text { than } 15 \\
\text { years; } \\
\text { diagnosis of } \\
\text { plantar }\end{array}$ & $\begin{array}{l}\text { 1. One session of } \\
\text { Shockwave therapy } \\
\text { (ESWT) and daily } \\
\text { Plantar fascia and } \\
\text { gastrocnemius }\end{array}$ & $\begin{array}{l}\text { Pain (VAS), } \\
\text { Function (VAS } \\
\text { activity, RMS) }\end{array}$ & $\begin{array}{l}\text { In the group of patients that } \\
\text { received ESWT, the median (and } \\
\text { interquartile range) of } \\
\text { improvement in the VAS of pain } \\
\text { result, when taking the first }\end{array}$ \\
\hline
\end{tabular}




\begin{tabular}{|c|c|c|c|}
\hline Spain & $\begin{array}{l}\text { fasciitis made } \\
\text { by a } \\
\text { physician and } \\
\text { symptoms of } \\
\text { at least 6- } \\
\text { month } \\
\text { duration. }\end{array}$ & $\begin{array}{l}\text { stretching }(n=37) \text {. } \\
2 \text {. One injection of } \\
\text { Botulinum toxin type A } \\
\text { and daily Plantar } \\
\text { fascia and } \\
\text { gastrocnemius } \\
\text { stretching }(n=37)\end{array}$ & $\begin{array}{l}\text { steps, was } 2(1-4) \text { points, and in } \\
\text { the group of patients that received } \\
\text { BoNT-A the same result was } 1 \text { ( } 0- \\
2 \text { ) points ( } 1 / 40.009) \text {. In the group } \\
\text { of patients that received ESWT, } \\
\text { the median (and interquartile } \\
\text { range) of improvement in the } \\
\text { Roles and Maudsley scale of pain } \\
\text { result was } 1(0-1) \text { points, and in } \\
\text { the group of patients that received } \\
\text { BoNT-A the same result was } 0 \text { ( } 0- \\
1 \text { ) points ( } 1 / 40.006) \text {. In a } \\
\text { multivariate analysis use of ESWT } \\
\text { and lower weight were associated } \\
\text { with improvement of pain with } \\
\text { treatment in at least one of the } \\
\text { three VAS of pain scales used in } \\
\text { the study. ESWT was superior to } \\
\text { BoNT-A in the control of pain in } \\
\text { patients with PF. }\end{array}$ \\
\hline
\end{tabular}

Abbreviations: BoNT-A: Botulinum toxin type-A; VAS: visual analogue scale; RMS: Roles and Maudsley score; AOFAS: American orthopaedic foot and ankle society scale; FFI: Foot Function Index: ESWT: Extracorporeal shockwave therapy; CFO: Custom fabricated orthotics: LLLT: Low-Level laser therapy: PHP: Plantar heel pain; FHSQ: Foot health status questionnaire; US: Ultrasound. 


\section{Discussion}

This systematic review investigated the effectiveness of combined ESWT and exercise interventions versus other interventions for pain and function in PHP. The findings suggest that combined ESWT and stretching treatment is superior to using either alone or botulinum toxin injection combined with stretching for improving pain and function in PHP. The combination of ESWT and stretching also appears to be more effective than combining ultrasound with stretching and has similar outcomes to combining LLLT or custom orthotics with stretching. When comparing ESWT and stretching with more invasive injection therapies such as ACP or corticosteroid injection, there was no significant difference between interventions. Combining ESWT and stretching with topical corticosteroid, dry needling or LLLT also led to superior outcomes. The GRADE strength of evidence rating was initially considered high for each of these outcomes, due to having high quality RCT evidence. However, as it pertains to ESWT and stretching being superior to ultrasound, this was downgraded to a 'low' strength of evidence due to potential bias (Table 2). These three studies were all unclear about randomization methods and if concealed allocation to treatment groups was used [63, 65, 66]. Two of these studies also did not disclose if outcome assessors were blind to group assignment $[65,66]$. Therefore, these studies could have introduced potential sampling and measurement bias [67]. Both studies were still included in the review as they still maintained an overall moderate score of $4 / 7$ but reduced the strength of the evidence compared to other interventions. Strength of evidence was downgraded from high to moderate for the comparison of ESWT and stretching to corticosteroid injection and the addition of dry needling due to risk of bias regarding unclear randomization methods and use of concealed allocation $[62,64]$.

Recent systematic reviews have also suggested similar outcomes with ESWT and CSI and ACP injection therapies for PHP $[8,68,69]$. This suggests these invasive injection therapies may be unnecessary if ESWT is available as a treatment option as it is associated with less side effects and a better safety profile [70-72]. Participants were also significantly more satisfied with ESWT vs CSI (55\% V 30\%) as a PHP treatment in the included study [62]. There was no significant difference 
between ESWT and stretching versus CFO and stretching, however CFO or standard orthotics are recommended as an earlier intervention strategy than ESWT [73]. Although systematic reviews have suggested no benefits of standardised orthotics for PHP [74], recent RCTs have shown effectiveness of CFO for PHP [75, 76]. The effectiveness of combined ESWT and stretching was also found to be increased when topical corticosteroid was used prior to ESWT and when LLLT was used following ESWT $[40,60]$. This is in keeping with previous studies, as both LLLT and CSI have been shown to be effective for treating PHP, although often not as effective as ESWT $[32,77,78]$. Although LLLT induces tissue regeneration and anti-inflammatory effects like ESWT, it is believed to work by a different mechanism by targeting cell mitochondria [79, 80]. Although CSI has been shown to be effective for short-term pain reduction and reducing inflammation in PHP [81], reported side effects include heel pad atrophy and plantar fascia rupture $[82,83]$. Studies in tendinopathy have also found that CSI can reduce effectiveness of exercise interventions and may therefore not be an optimal treatment combination $[84,85]$.

Although combined PHP treatments can increase intervention effectiveness, they may be impractical and not cost-effective in many clinical settings [42]. Out of all PHP treatments, ESWT may not only be the most effective treatment option to combine with exercise but also the most practical and safest [19]. It is less invasive, has less side effects and has better long-term effectiveness than ACP or CSI injection therapies $[29,32,86]$. It also requires less treatment sessions, with 3 being recommended, compared to LLLT or ultrasound which typically requires 10-15 treatment sessions [87]. All the studies that have used exercise alongside ESWT as an intervention have used stretching interventions including the same PFSS protocol [20]. However, the use of a standardized 12-week heavy slow resistance training (HSRT) program targeting the plantar fascia was found more effective compared to this PFSS protocol for pain (VAS) and function (FFI) in a RCT [21]. A recent RCT found that combining HSRT and PFSS protocols with CSI, was significantly more effective than CSI or the combined exercise program alone for pain and function (VAS and FFI) in PHP [41]. Hip strengthening exercise targeting kinetic chain strength deficits not addressed by heel-raise protocols in isolation have also been found to have positive effects for PHP [24, 88-90]. 
Currently, no studies have investigated the effects of strengthening exercise combined with ESWT for PHP [23].

\section{Main limitations of included studies}

The main limitations of studies included in this review relate to small sample sizes, methodological and clinical heterogeneity in study designs, and the lack of blinding in some studies leading to a risk of bias. Only some studies conducted power calculations for sample sizes $[33,40,42,60,62,63]$ resulting in some studies being potentially underpowered to detect true statistically significant differences $[58,59,61,64,65]$. One study claimed to have used a power calculation, but details of the sample size obtained from it were omitted [66]. There was a wide variation in intervention protocols. Different types of ESWT were used, with different energy densities, different machines and various numbers of treatment sessions, ranging from two [58] to five [62], with three being most common. All these parameters are known to influence effectiveness of ESWT [91].

There were also wide variations in longest treatment follow-up times, ranging from one month [66] to 24 months [33], with only three studies having a 12-month or longer follow-up $[33,59,65]$. Treatment interventions also varied in length, from three weeks [40, 42, 63] to eight weeks [33]. There were also variances in the participant criteria, such as duration of PHP and diagnostic methods. Duration of PHP ranged from one month [42] to 12 months [33], with three months being the average. This is important as duration of PHP is known to affect outcomes to ESWT [71]. The recommended length of PFSS intervention is eight weeks in order to have physiological effects [20]. Although all studies referred to the same PFSS protocol [20], only one study implemented it with an eight-week intervention [33]. This leads to uncertainty over the true effectiveness of PFSS or its additive effect to ESWT within these studies. Most studies also included gastrocnemius stretching alongside PFSS, which may have influenced outcomes, however the superiority of

PFSS over gastrocnemius stretching for PHP has been well documented [21]. Some studies gave exercise instructions and adherence diaries, but these were 
poorly reported, raising concerns on exercise adherence [92-94]. Although most studies used VAS scales to measure pain, various outcome measures were used to evaluate foot function. The FFI was the only outcome measure used which has been specifically validated for the PHP population [49], however only four studies used the complete FFI $[59,62,64,66]$.

\section{Limitations of the review}

Due to study heterogeneity, statistical pooling and meta-analysis was not possible which limits the conclusions that can be drawn regarding the effectiveness of combined ESWT and exercise interventions versus other interventions in treating PHP [53]. A few non-English articles were excluded which influences the generalizability of findings since treatment methods may differ by country. Half of the included studies (6 of 12) originated from either Turkey or Iran, which influences global generalizability of findings [95]. Although a thorough search for literature was conducted, it is still possible that relevant literature may have been missed, which may have affected the review outcomes [54].

\section{Implications and recommendations for practice and research}

The evidence from this systematic review suggests that combined ESWT and stretching interventions are an effective treatment for PHP compared to other treatments. There is high- and low-quality evidence that this combined approach is more effective than either alone or ultrasound. Therefore, clinical recommendations may be made that combined ESWT and stretching should be recommended in favour of either alone or ultrasound. Although there were no significant differences in effectiveness between combined ESWT and stretching with injection therapies ( $A C P, C S I)$, ESWT may be recommended over them as they have a better safety profile and less side effects. Topical corticosteroid may be a safer option which has been shown to have an additive short-term effect when combined with ESWT and stretching and may be recommended where available $[60,96]$. Although there was no difference between combined ESWT and 
stretching and CFO, standard or custom orthotics are consistently recommended alongside or prior to ESWT [97-99].

There are conflicting and mixed findings when ESWT and stretching is compared with LLLT and stretching, with neither method appearing superior. However, ESWT should be considered a more practical and cost-effective method compared to LLLT, as the recommended standardized ESWT protocol requires 3 sessions to be effective, whereas LLLT requires 10-15 sessions [40]. Given that LLLT requires up to 15 sessions and the side effects associated with corticosteroids, a combined ESWT ( 3 sessions) and stretching protocol may be the most practical, costeffective, safest and evidence-based conservative treatment currently available for PHP. The review findings support the recommendations from recent PHP reviews that combined rather than single interventions should be recommended for treating PHP $[43,99]$.

Further large-scale RCTs should be conducted with large sample sizes and robust methods to control for assessor bias, such as ensuring blinding of those assessing outcome measures. Longer-term follow-up times are also required in order to determine long-term effectiveness of combined PHP interventions. Future studies should investigate and compare combined interventions using validated measures, which is reflective of clinical physiotherapy practice, where treatments are often combined [42]. Different types of exercise other than stretching should be combined with ESWT, such as HSRT [13]. Using standardized intervention protocols and validated outcome measures would also allow better translation of findings $[38,100,101]$. Future studies should also emphasise the importance of returning exercise diaries to monitor adherence [13]. Recently, several psychological and nutritional PHP risk factors have been identified, therefore future studies could investigate psychological and nutritional interventions alongside physiotherapy in a biopsychosocial treatment model [102-110]. 


\title{
Table 2: Summary of findings table
}

\author{
Summary of findings:
}

\section{ESWT and stretching compared to other treatments for Plantar heel pain}

Patient or population: Plantar heel pain

Setting: Any clinical setting

Intervention: ESWT and stretching

Comparison: other treatments

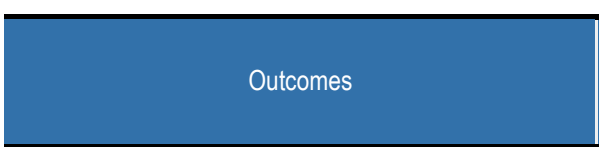

Pain and function in PHP with combined ESWT and stretching versus stretching alone follow up: range 1 months to 6 months

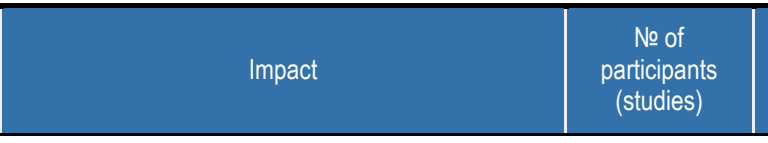

ESWT and stretching statistically significantly superior for improving pain and function
Certainty of the

evidence

(GRADE)

\section{Pain and function in PHP with combined ESWT} and stretching versus ESWT alone

follow up: range 2 months to 24 months

ESWT and stretching statistically significantly superior for improving pain and function

Pain and function in PHP with combined ESWT

ESWT and stretching statistically significantly and stretching versus ultrasound combined with superior for improving pain and function

follow up: range 1 months to 12 months

Pain and function in PHP with combined ESWT and stretching versus $A C P$ injection combined with stretching follow up: 6 months
Mixed findings - neither treatment statistically significantly superior for improving pain and function

$\begin{array}{cc}54 & \bigoplus \text { (1 RCT) } \\ \text { HIGH }\end{array}$

Pain and function in PHP with combined ESWT and stretching versus corticosteroid injection combined with stretching follow up: 2 months
Mixed findings - neither treatment statistically significantly superior for improving pain and function

$\begin{array}{cc}40 & \oplus \bigoplus \bigoplus \bigcirc \\ (1 \mathrm{RCT}) & \text { MODERATE }\end{array}$

Pain and function in PHP with combined ESWT and stretching versus LLLT combined with stretching follow up: range 1 months to 3 months
Mixed findings - neither treatment statistically significantly superior for improving pain and function

\section{Pain and function in PHP with combined ESWT \\ Mixed findings - neither treatment statistically and stretching versus CFO combined with stretching significantly superior for improving pain and function \\ follow up: 11 months}

Pain and function in PHP with combined ESWT and stretching versus botulinum toxin type $A$ injection combined with stretching follow up: 2 months

\section{ESWT and stretching statistically significantly} superior for improving pain and function 


\section{ESWT and stretching compared to other treatments for Plantar heel pain}

Patient or population: Plantar heel pain

Setting: Any clinical setting

Intervention: ESWT and stretching

Comparison: other treatments

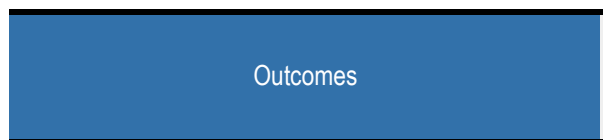

Pain and function in PHP with dry needling combined with ESWT and stretching versus dry needling and stretching follow up: 1 months

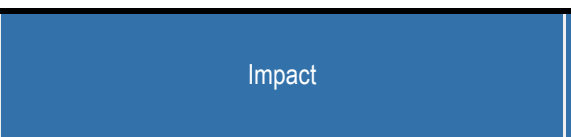

Dry needling combined with ESWT and stretching statistically significantly superior for improving pain and function

(1 RCT) MODERATE

Pain and function in PHP with topical corticosteroid combined with ESWT and stretching versus ESWT and stretching follow up: 3 months
Topical corticosteroid combined with ESWT and stretching statistically significantly superior for improving pain and function
(1 RCT)

$\bigoplus \bigoplus \bigoplus \bigoplus$

$\mathrm{HIGH}$
Pain and function in PHP with LLLT combined with ESWT and stretching versus ESWT and stretching follow up: 3 months
LLLT combined with ESWT and stretching statistically significantly superior for improving pain and function

60

(1 RCT)

$\oplus \oplus \oplus \oplus$

HIGH

\footnotetext{
${ }^{*}$ The risk in the intervention group (and its $95 \%$ confidence interval) is based on the assumed risk in the comparison group and the relative effect of the intervention (and its $95 \% \mathrm{Cl}$ ).

\section{Cl: Confidence interval}

\section{GRADE Working Group grades of evidence}

High certainty: We are very confident that the true effect lies close to that of the estimate of the effect

Moderate certainty: We are moderately confident in the effect estimate: The true effect is likely to be close to the estimate of the effect, but there is a possibility that it is substantially different

Low certainty: Our confidence in the effect estimate is limited: The true effect may be substantially different from the estimate of the effect Very low certainty: We have very little confidence in the effect estimate: The true effect is likely to be substantially different from the estimate of effect
}

\section{Explanations}

a. Unclear randomization methods and if concealed allocation was used. Did not disclose if outcome assessors were blinded to group assignment. Potential sampling and measurement bias.

b. Unclear allocation concealment (potential selection bias) 


\section{Conclusion}

Plantar heel pain is a very common musculoskeletal disorder, with a significant burden on society, requiring effective evidence-based treatment interventions. This systematic review sought to investigate the effectiveness of combined ESWT and exercise interventions versus other common interventions in improving pain and function in PHP. Twelve RCTs met the inclusion/exclusion criteria $(n=861)$ with various commonly used comparator interventions. Given the clinical and methodological heterogeneity of included studies, statistical pooling of data for meta-analysis was not possible. Therefore, a narrative synthesis of findings was presented, with quality of evidence assessed by GRADE. There is high quality evidence that combined ESWT and stretching interventions are more effective than those using either alone or BoNT-A injection, with low quality evidence versus ultrasound interventions. There was moderate quality evidence that combined ESWT and stretching is no more effective than corticosteroid injection, and high quality evidence that the combination is no more effective than autologous conditioned plasma injection, custom orthotics or low-level laser therapy combined with stretching. However, ESWT and stretching should be considered as a safer and more practical treatment option than these methods. There was high quality evidence that the use of topical corticosteroid or LLLT in combination with ESWT and stretching increases effectiveness compared to ESWT and stretching alone, and moderate quality evidence for dry needling in combination with ESWT and stretching. The combined treatments for PHP with quality evidence may be recommended where they are available and practical to implement. This review supports recent recommendations in the literature for using combined rather than single treatments for PHP $[41,43,99]$. The combination of ESWT and stretching may be the most practical and effective treatment currently available with high quality evidence. Recently, HSRT has been shown to be superior to stretching, but HSRT or other strengthening exercises have not been investigated either combined with or compared against ESWT as a PHP treatment in RCTs. Further high-quality RCTs with robust methodological design, larger sample sizes and longer follow-up durations comparing combined interventions for PHP are required in order to determine and recommend the most optimal treatment strategy. 


\section{Acknowledgments}

None.

Funding: No sources of funding were used to assist in the preparation of this article.

Conflicts of interest/Competing interests: The author declares no conflicts of interest relevant to the content of this review.

Authorship contributions: IB conceptualised the work, wrote the first draft of the manuscript, revised the manuscript and approved the final manuscript. 


\section{Appendices}

\section{Appendix 1: Studies excluded on full text review}

1. [111]. Akinoglu B, Kose N. A comparison of the acute effects of radial extracorporeal shockwave therapy, ultrasound therapy, and exercise therapy in plantar fasciitis. J Exerc Rehabil. 2018 Apr 26;14(2):306-12.

Reason for exclusion: Duplication of data

2. [112]. Eun SS, Chachan S, Lee SH. Effectiveness of a double air-cushioned shoe compared with physiotherapy in the treatment of plantar fasciitis. Biomed Res Int. 2020 04/02;2020:9468302.

Reason for exclusion: Wrong study design

3. [113]. Greve JM, Grecco MV, Santos-Silva PR. Comparison of radial shockwaves and conventional physiotherapy for treating plantar fasciitis. Clinics (Sao Paulo). 2009;64(2):97-103.

Reason for exclusion: Duplication of data

4. [114]. Krukowska J, Wrona J, Sienkiewicz M, Czernicki J. A comparative analysis of analgesic efficacy of ultrasound and shock wave therapy in the treatment of patients with inflammation of the attachment of the plantar fascia in the course of calcaneal spurs. Arch Orthop Trauma Surg. 2016 Sep;136(9):1289-96.

Reason for exclusion: Wrong intervention

5. [115]. Melegati G, Tornese D, Bandi M, Caserta A. The influence of local steroid injections, body weight and the length of symptoms in the treatment of painful 
subcalcaneal spurs with extracorporeal shock wave therapy. Clin Rehabil. 2002 $11 ; 16(7): 789-94$.

Reason for exclusion: Wrong study design

6. [116]. Porter MD, Shadbolt B. Intralesional corticosteroid injection versus extracorporeal shock wave therapy for plantar fasciopathy. Clin J Sport Med. 2005 May;15(3):119-24.

Reason for exclusion: Wrong outcome: did not measure function

7. [90]. Wheeler PC, Tattersall C. Extracorporeal shockwave therapy plus rehabilitation for patients with chronic plantar fasciitis might reduce pain and improve function but still not lead to increased activity: A case-series study with multiple outcome measures. J Foot Ankle Surg. 2018 Mar - Apr;57(2):339-45.

Reason for exclusion: Wrong study design

8. [87]. Uğurlar M, Sönmez MM, Uğurlar ÖY, Adıyeke L, Yıldırım H, Eren OT. Effectiveness of four different treatment modalities in the treatment of chronic plantar fasciitis during a 36-month follow-up period: A randomized controlled trial. J Foot Ankle Surg. 2018 09/20;57(5):913-8.

Reason for exclusion: Wrong intervention 


\section{Appendix 2: MEDLINE search strategy:}

Full search strategy for Medline (EBSCOhost). Search conducted on $16^{\text {th }}$ March 2020.

\begin{tabular}{|l|l|l|}
\hline Search & Query & $\begin{array}{l}\text { Records } \\
\text { retrieved }\end{array}$ \\
\hline$\# 1$ & $\begin{array}{l}\text { MH extracorporeal shockwave therapy OR KW } \\
\text { shock wave therapy OR KW shockwave therapy OR } \\
\text { KW shock wave treatment OR KW shockwave* OR } \\
\text { KW ESWT }\end{array}$ & 4,025 \\
\hline \#2 & $\begin{array}{l}\text { MH fasciitis, plantar OR KW plantar OR KW heel } \\
\text { pain OR KW plantar fasciitis OR KW plantar } \\
\text { fasciopathy }\end{array}$ & $\begin{array}{l}\text { MH exercise OR MH physical therapy modalities OR } \\
\text { MH physical therapy specialty OR KW } \\
\text { physiotherapy OR KW physical therapy OR KW } \\
\text { usual care OR KW standard care OR KW stretching } \\
\text { OR KW strengthening OR KW corticosteroid }\end{array}$ \\
\hline \#1 AND \#2 AND \#3 & 112 \\
\hline L4 & Limited to English language, year 2000 - 2020 & \\
\hline
\end{tabular}




\section{Appendix 3: Search strategy by database}

Medline search strategy

( $\mathrm{MH}$ extracorporeal shockwave therapy OR TX ( shock wave therapy OR shockwave therapy OR shock wave treatment OR shockwave* OR ESWT ) ) AND ( MH fasciitis, plantar OR TX ( OR plantar OR heel pain OR plantar fasciitis OR plantar fasciopathy ) ) AND ( MH ( exercise OR physical therapy modalities OR physical therapy specialty ) OR TX ( physiotherapy OR physical therapy OR usual care OR standard care OR stretching OR strengthening OR corticosteroid) )

Studies found: 112

CINAHL search strategy

( MH ultrasonics OR TX ( extracorporeal shockwave therapy OR shock wave therapy OR shockwave therapy OR shock wave treatment OR shockwave* OR ESWT ) ) AND ( MH plantar fasciitis OR TX ( OR plantar OR heel pain OR plantar fasciitis OR plantar fasciopathy ) ) AND ( MH ( exercise OR stretching OR physical therapy OR physical therapy practice, research-based ) OR TX ( physiotherapy OR usual care OR standard care OR strengthening OR corticosteroid) )

Studies found: 127

\section{SPORTDiscus search strategy}

( $\mathrm{MH}$ extracorporeal shock wave therapy OR TX ( extracorporeal shockwave therapy OR shock wave therapy OR shockwave therapy OR shock wave treatment OR shockwave* OR ESWT ) ) AND ( MH PLANTAR fasciitis OR TX ( OR plantar OR heel pain OR plantar fasciitis OR plantar fasciopathy ) ) AND ( MH ( exercise OR stretch (physiology) OR static stretching (physiology) OR physical therapy ) OR TX ( physiotherapy OR usual care OR standard care OR strengthening OR stretching OR corticosteroid) )

Studies found: 147 
AMED search strategy

( $\mathrm{MH}$ shockwave therapy OR TX ( extracorporeal shockwave therapy OR extracorporeal shock wave therapy OR shock wave therapy OR shockwave therapy OR shock wave treatment OR shockwave* OR ESWT ) ) AND ( MH plantar fasciitis OR TX ( OR plantar OR heel pain OR plantar fasciitis OR plantar fasciopathy ) ) AND ( $\mathrm{MH}$ ( exercise OR exercise therapy OR stretching OR physiotherapy physical therapy modalities OR physical therapy specialty OR physical therapy techniques ) OR TX ( physical therapy OR usual care OR standard care OR strengthening OR stretching OR corticosteroid) )

Studies found: 19

Total studies included for screening: 405 


\section{Appendix 4: Executive summary}

Review title: The effectiveness of combined extracorporeal shockwave therapy and exercise for plantar heel pain: A systematic review.

Objective: This review aimed to evaluate the effectiveness of combined extracorporeal shockwave therapy (ESWT) and exercise interventions versus any other interventions in improving pain and function in plantar heel pain (PHP).

Introduction: PHP is one of the most common musculoskeletal disorders and represents a significant burden, with both ESWT and exercise shown to be effective treatments. Despite the increasing evidence for combining ESWT and specific exercises for PHP, the optimal treatment protocol remains unknown, with clinical recommendations lacking. There are currently no systematic reviews comparing the effectiveness of combined ESWT and exercise versus other treatment methods for PHP. Therefore, the aim of this work was to conduct such a systematic review and make recommendations based on the quality of the evidence.

Inclusion criteria: The review sought to include randomised controlled trials (RCTs) that have investigated the combined effect of ESWT and exercise in the treatment of PHP compared with other interventions. Participants were adults aged 18 years or older and formally diagnosed with PHP. Primary outcomes were heel pain and foot function measured by validated measures such as visual analogue scale (VAS) and the foot function index (FFI).

Methods: A three-step search strategy was employed. Following initial searching of Medline and CINAHL and analysis of text words, seven databases were searched in March 2020. Reference lists of studies included at the critical appraisal stage were hand-searched to identify any additional studies. Studies published in English from 2000 onwards were included. Searching identified 405 studies, with 20 reviewed in full-text, 12 of which met the inclusion criteria. Following title and abstract screening, critical appraisal, and data extraction of included studies were 
conducted by the author via tools on Covidence. The Grading of Recommendations Assessment Development and Evaluation (GRADE) framework was used to determine quality of evidence.

Results: The 12 included RCTs were conducted in a range of countries: Turkey (4), Iran (2), Egypt, Brazil, Germany, Singapore, Canada and Spain. All the studies were conducted within a healthcare setting, and there was a total of 861 participants. All studies investigated the effects of the interventions on heel pain and foot function using a variety of validated measures. The studies used a variety of comparator interventions compared to ESWT and exercise, with some having three or four trial arms comparing multiple combined interventions. The only exercise interventions used were plantar fascia specific stretching (PFSS) and gastrocnemius stretching. The highest quality score available was 6-7/7, with seven studies achieving this score, two studies scored five and the remaining two scored four. Pooling of data in a meta-analysis was not possible, and a narrative synthesis of findings was developed. There was high quality evidence that combined ESWT and stretching interventions are more effective than those using either alone or compared to botulinum toxin injection combined with stretching. There was low-quality evidence that the combination is no more effective than ultrasound and stretching interventions. There was moderate quality evidence that combined ESWT and stretching is no more effective than corticosteroid injection (CSI), and high quality evidence that the combination is no more effective than blood-derived injection therapies, custom orthotics or low-level laser therapy (LLLT) combined with stretching. There was high quality evidence that the use of topical corticosteroid or LLLT in combination with ESWT and stretching increases effectiveness compared to ESWT and stretching alone, and moderate quality evidence for dry needling in combination with ESWT and stretching.

Conclusions: Due to consistent high-quality evidence of effectiveness, combined ESWT and stretching treatments may be recommended. The use of additional CSI or LLLT may also be recommended, where they are available and practical to implement. Further high-quality RCTs with larger sample sizes and longer followup durations comparing combined interventions for PHP are required in order to determine the optimal treatment strategy. Future studies should also investigate strength exercise combined with or compared against ESWT as a PHP treatment. 


\section{Appendix 5: Abbreviations}

ACP - Autologous conditioned plasma

BoTN-A - Botulinum toxin type-A

CFO - Custom fabricated orthotics

CSI - Corticosteroid injection

ESWT - Extracorporeal shock wave therapy

FFI - Foot Function Index

FFI-PS - Foot Function Index pain subscale

GRADE - Grading of Recommendations, Assessment, Development and Evaluation

HSRT - Heavy slow resistance training

LLLT - Low-level laser therapy

NHS- National Health Service

NSAIDS - Non-steroidal anti-inflammatory drugs

PBMT - Photo-biomodulation therapy

PFSS - Plantar fascia specific stretching

PHP - Plantar heel pain

PRISMA - Preferred Reporting Items for Systematic Reviews and Meta-Analysis

RCTs - Randomised controlled trials

RMS - Roles and Maudsley score

UK - United Kingdom 


\section{References}

1. Safiri S, Kolahi AA, Cross M, Carson-Chahhoud K, Almasi-Hashiani A, Kaufman J, et al. Global, regional, and national burden of other musculoskeletal disorders 1990-2017: Results from the global burden of disease study 2017. Rheumatology (Oxford). 2020 Aug 25.

2. Sebbag E, Felten R, Sagez F, Sibilia J, Devilliers H, Arnaud L. The world-wide burden of musculoskeletal diseases: A systematic analysis of the world health organization burden of diseases database. Ann Rheum Dis. 2019 Jun;78(6):844-8.

3. Hoy DG, Smith E, Cross M, Sanchez-Riera L, Blyth FM, Buchbinder R, et al. Reflecting on the global burden of musculoskeletal conditions: Lessons learnt from the global burden of disease 2010 study and the next steps forward. Ann Rheum Dis. 2015 Jan;74(1):4-7.

4. March L, Smith EU, Hoy DG, Cross MJ, Sanchez-Riera L, Blyth F, et al. Burden of disability due to musculoskeletal (MSK) disorders. Best Pract Res Clin Rheumatol. 2014 Jun;28(3):353-66.

5. Blyth FM, Briggs AM, Schneider CH, Hoy DG, March LM. The global burden of musculoskeletal pain-where to from here? Am J Public Health. 2019 Jan;109(1):35-40.

6. Trojian T, Tucker AK. Plantar fasciitis. Am Fam Physician. 2019 06/15;99(12):744-50.

7. Karagounis P, Tsironi M, Prionas G, Tsiganos G, Baltopoulos P. Treatment of plantar fasciitis in recreational athletes: Two different therapeutic protocols. Foot Ankle Spec. 2011 Aug;4(4):226-34.

8. Al-Boloushi $Z$, López-Royo MP, Arian M, Gómez-Trullén EM, Herrero P. Minimally invasive non-surgical management of plantar fasciitis: A systematic review. Journal of Bodywork \& Movement Therapies. 2019 01;23(1):122-37. 
9. Hasegawa M, Urits I, Orhurhu V, Orhurhu MS, Brinkman J, Giacomazzi S, et al. Current concepts of minimally invasive treatment options for plantar fasciitis: A comprehensive review. Curr Pain Headache Rep. 2020 Aug $12 ; 24(9): 55,020-00883-7$.

10. Hansen L, Krogh TP, Ellingsen T, Bolvig L, Fredberg U. Long-Term Prognosis of Plantar Fasciitis: A 5- to 15-Year Follow-up Study of 174 Patients With Ultrasound Examination. Orthop J Sports Med 2018 Mar $6 ; 6(3): 2325967118757983$.

11. Gollwitzer H, Saxena A, DiDomenico LA, Galli L, Bouche RT, Caminear DS, et al. Clinically relevant effectiveness of focused extracorporeal shock wave therapy in the treatment of chronic plantar fasciitis: A randomized, controlled multicenter study. J Bone Joint Surg Am. 2015 May 6;97(9):701-8.

12. Monteagudo M, de Albornoz PM, Gutierrez B, Tabuenca J, Alvarez I. Plantar fasciopathy: A current concepts review. EFORT Open Rev. 2018 Aug $29 ; 3(8): 485-93$.

13. Riel H, Jensen MB, Olesen JL, Vicenzino B, Rathleff MS. Self-dosed and predetermined progressive heavy-slow resistance training have similar effects in people with plantar fasciopathy: A randomised trial. J Physiother. 2019 Jul;65(3):144-51.

14. Rasenberg N, Bierma-Zeinstra SMA, Fuit L, Rathleff MS, Dieker A, van Veldhoven $P$, et al. Custom insoles versus sham and GP-led usual care in patients with plantar heel pain: Results of the STAP-study - a randomised controlled trial. Br J Sports Med. 2020 Sep 2.

15. Salvioli S, Guidi M, Marcotulli G. The effectiveness of conservative, nonpharmacological treatment, of plantar heel pain: A systematic review with meta-analysis. Foot (Edinb). 2017 Dec; 33:57-67. 
16. Shetty SH, Dhond A, Arora M, Deore S. Platelet-rich plasma has better long-term results than corticosteroids or placebo for chronic plantar fasciitis: Randomized control trial. J Foot Ankle Surg. 2019 Jan;58(1):42-6.

17. Jastifer JR, Catena F, Doty JF, Stevens F, Coughlin MJ. Low-level laser therapy for the treatment of chronic plantar fasciitis: A prospective study. Foot Ankle Int. 2014 Jun;35(6):566-71.

18. Sun $\mathrm{K}$, Zhou H, Jiang W. Extracorporeal shock wave therapy versus other therapeutic methods for chronic plantar fasciitis. Foot Ankle Surg. 2020 Jan;26(1):33-8.

19. Babatunde OO, Legha A, Littlewood C, Chesterton LS, Thomas MJ, Menz $H B$, et al. Comparative effectiveness of treatment options for plantar heel pain: A systematic review with network meta-analysis. $\mathrm{Br}$ J Sports Med. 2019 $02 ; 53(3): 182-94$.

20. Digiovanni BF, Nawoczenski DA, Malay DP, Graci PA, Williams TT, Wilding $\mathrm{GE}$, et al. Plantar fascia-specific stretching exercise improves outcomes in patients with chronic plantar fasciitis. A prospective clinical trial with two-year follow-up. J Bone Joint Surg Am. 2006 Aug;88(8):1775-81.

21. Rathleff MS, Molgaard CM, Fredberg U, Kaalund S, Andersen KB, Jensen $\Pi$, et al. High-load strength training improves outcome in patients with plantar fasciitis: A randomized controlled trial with 12-month follow-up. Scand J Med Sci Sports. 2015 Jun;25(3):e292-300.

22. Riel H, Vicenzino B, Jensen MB, Olesen JL, Holden S, Rathleff MS. The effect of isometric exercise on pain in individuals with plantar fasciopathy: $A$ randomized crossover trial. Scand J Med Sci Sports. 2018 Sep 11.

23. Huffer D, Hing W, Newton R, Clair M. Strength training for plantar fasciitis and the intrinsic foot musculature: A systematic review. Phys Ther Sport. 2017 Mar;24:44-52. 
24. Kamonseki DH, Goncalves GA, Yi LC, Junior IL. Effect of stretching with and without muscle strengthening exercises for the foot and hip in patients with plantar fasciitis: A randomized controlled single-blind clinical trial. Man Ther. 2016 Jun;23:76-82.

25. Mani-Babu S, Morrissey D, Waugh C, Screen H, Barton C. The effectiveness of extracorporeal shock wave therapy in lower limb tendinopathy: A systematic review. Am J Sports Med. 2015 Mar;43(3):752-61.

26. Romeo P, Lavanga V, Pagani D, Sansone V. Extracorporeal shock wave therapy in musculoskeletal disorders: A review. Med Princ Pract. 2014;23(1):7-13.

27. Gerdesmeyer L, Frey C, Vester J, Maier M, Weil L,Jr, Weil LS, et al. Radial extracorporeal shock wave therapy is safe and effective in the treatment of chronic recalcitrant plantar fasciitis: Results of a confirmatory randomized placebo-controlled multicenter study. Am J Sports Med. 2008 Nov;36(11):2100-9.

28. Lou J, Wang S, Liu S, Xing G. Effectiveness of extracorporeal shock wave therapy without local anesthesia in patients with recalcitrant plantar fasciitis: A meta-analysis of randomized controlled trials. Am J Phys Med Rehabil. 2017 Aug;96(8):529-34.

29. Li H, LV H, Lin T. Comparison of efficacy of eight treatments for plantar fasciitis: A network meta-analysis. J Cell Physiol. 2018 01;234(1):860-70.

30. Li H, Xiong Y, Zhou W, Liu Y, Liu J, Xue H, et al. Shock-wave therapy improved outcome with plantar fasciitis: A meta-analysis of randomized controlled trials. Arch Orthop Trauma Surg. 2019 12;139(12):1763-70.

31. Li X, Zhang L, Gu S, Sun J, Qin Z, Yue J, et al. Comparative effectiveness of extracorporeal shock wave, ultrasound, low-level laser therapy, noninvasive interactive neurostimulation, and pulsed radiofrequency treatment for treating plantar fasciitis: A systematic review and network meta-analysis. Medicine (Baltimore). 2018 10;97(43):e12819-. 
32. Xiong Y, Wu Q, Mi B, Zhou W, Liu Y, Liu J, et al. Comparison of efficacy of shock-wave therapy versus corticosteroids in plantar fasciitis: A meta-analysis of randomized controlled trials. Arch Orthop Trauma Surg. 2019 $04 ; 139(4): 529-36$.

33. Rompe JD, Furia J, Cacchio A, Schmitz C, Maffulli N. Radial shock wave treatment alone is less efficient than radial shock wave treatment combined with tissue-specific plantar fascia-stretching in patients with chronic plantar heel pain. Int J Surg. 2015 Dec;24(Pt B):135-42.

34. van der Worp $H$, van den Akker-Scheek I, van Schie H, Zwerver J. ESWT for tendinopathy: Technology and clinical implications. Knee Surg Sports Traumatol Arthrosc. 2013 Jun;21(6):1451-8.

35. Ueberle F, Rad AJ. Characterization of unfocused / weakly focused pressure pulse sources for extracorporeal pain therapy ("radial shock wave therapy" sources). Biomed Tech (Berl). 2013 Sep 7.

36. Moya D, Ramon S, Schaden W, Wang CJ, Guiloff L, Cheng JH. The role of extracorporeal shockwave treatment in musculoskeletal disorders. J Bone Joint Surg Am. 2018 Feb 7;100(3):251-63.

37. Wang CJ, Cheng JH, Chou WY, Hsu SL, Chen JH, Huang CY. Changes of articular cartilage and subchondral bone after extracorporeal shockwave therapy in osteoarthritis of the knee. Int J Med Sci. 2017 Feb 23;14(3):21323.

38. Lohrer H, Nauck T, Korakakis V, Malliaropoulos N. Historical ESWT paradigms are overcome: A narrative review. Biomed Res Int. $2016 ; 2016: 3850461$.

39. Gaida JE, Cook J. Treatment options for patellar tendinopathy: Critical review. Curr Sports Med Rep. 2011 Sep-Oct;10(5):255-70. 
40. Takla MKN, Rezk SSR. Clinical effectiveness of multi-wavelength photobiomodulation therapy as an adjunct to extracorporeal shock wave therapy in the management of plantar fasciitis: a randomized controlled trial. Lasers Med Sci 2019;34:583-93.

41. Johannsen FE, Herzog RB, Malmgaard-Clausen NM, Hoegberget-Kalisz M, Magnusson SP, Kjaer M. Corticosteroid injection is the best treatment in plantar fasciitis if combined with controlled training. Knee Surg Sports Traumatol Arthrosc. 2019 Jan;27(1):5-12.

42. Cinar E, Saxena S, Uygur F. Combination therapy versus exercise and orthotic support in the management of pain in plantar fasciitis: A randomized controlled trial. Foot Ankle Int. 2018 Jan 1:1071100717747590.

43. Cinar E, Saxena S, Akkurt HE, Uygur F. Extracorporeal shockwave therapy in the management of plantar fasciitis: A randomized controlled trial. Foot (Edinb). 2020 Sep;44:101679.

44. Aromataris E, Munn Z. e. Joanna Briggs Institute reviewer's manual [Internet]. The Joanna Briggs Institute, The University of Adelaide South Australia; 2020 [cited 2020 Oct 29]: [487 p.]. Available from:

https://reviewersmanual.joannabriggs.org/

45. Ibrahim MI, Donatelli RA, Hellman M, Hussein AZ, Furia JP, Schmitz C. Long-term results of radial extracorporeal shock wave treatment for chronic plantar fasciopathy: A prospective, randomized, placebo-controlled trial with two years follow-up. J Orthop Res. 2017 07;35(7):1532-8.

46. Budiman-Mak E, Conrad KJ, Mazza J, Stuck RM. A review of the foot function index and the foot function index - revised. J Foot Ankle Res. 2013 Feb $1 ; 6(1): 5,1146-6-5$.

47. Boonstra AM, Schiphorst Preuper HR, Reneman MF, Posthumus JB, Stewart RE. Reliability and validity of the visual analogue scale for disability in patients with chronic musculoskeletal pain. Int J Rehabil Res. 2008 Jun;31(2):165-9. 
48. Budiman-Mak E, Conrad K, Stuck R, Matters M. Theoretical model and rasch analysis to develop a revised foot function index. Foot Ankle Int. 2006 Jul;27(7):519-27.

49. Martin RL, Davenport TE, Reischl SF, McPoil TG, Matheson JW, Wukich DK, et al. Heel pain-plantar fasciitis: Revision 2014. J Orthop Sports Phys Ther. 2014 Nov;44(11):A1-33.

50. Herdman M, Gudex C, Lloyd A, Janssen M, Kind P, Parkin D, et al. Development and preliminary testing of the new five-level version of EQ-5D (EQ-5D-5L). Qual Life Res. 2011 Dec;20(10):1727-36.

51, Arah OA. Bias analysis for uncontrolled confounding in the health sciences. Annu Rev Public Health. 2017 Mar 20;38:23-38.

52. Guyatt G, Oxman AD, Akl EA, Kunz R, Vist G, Brozek J, et al. GRADE guidelines: 1 . introduction-GRADE evidence profiles and summary of findings tables. J Clin Epidemiol. 2011 Apr;64(4):383-94.

53, Charrois TL. Systematic reviews: What do you need to know to get started? Can J Hosp Pharm. 2015 Mar-Apr;68(2):144-8.

54. Roque M, Martinez-Garcia L, Sola I, Alonso-Coello P, Bonfill X, Zamora J. Toolkit of methodological resources to conduct systematic reviews. F1000Res. 2020 Feb 4;9:82.

55. Balshem H, Helfand M, Schunemann HJ, Oxman AD, Kunz R, Brozek J, et al. GRADE guidelines: 3. rating the quality of evidence. J Clin Epidemiol. 2011 Apr;64(4):401-6.

56. Guyatt GH, Oxman AD, Schunemann HJ, Tugwell P, Knottnerus A. GRADE guidelines: A new series of articles in the journal of clinical epidemiology. J Clin Epidemiol. 2011 Apr;64(4):380-2. 
57. Mustafa RA, Santesso N, Brozek J, Akl EA, Walter SD, Norman G, et al. The GRADE approach is reproducible in assessing the quality of evidence of quantitative evidence syntheses. J Clin Epidemiol. 2013 Jul;66(7):736,42; quiz 742.e1-5.

58. Chew KT, Leong D, Lin CY, Lim KK, Tan B. Comparison of autologous conditioned plasma injection, extracorporeal shockwave therapy, and conventional treatment for plantar fasciitis: A randomized trial. PM R. 2013 Dec; 5(12): 1035-43.

59. Çağlar Okur S, Aydın A. Comparison of extracorporeal shock wave therapy with custom foot orthotics in plantar fasciitis treatment: A prospective randomized one-year follow-up study. J Musculoskelet Neuronal Interact. 2019 $06 / 01 ; 19(2): 178-86$.

60. Vahdatpour B, Mokhtarian A, Raeissadat SA, Dehghan F, Nasr N, Mazaheri M. Enhancement of the effectiveness of extracorporeal shock wave therapy with topical corticosteroid in treatment of chronic plantar fasciitis: A randomized control clinical trial. Adv Biomed Res. 2018 04/24;7:62-.

61. Roca B, Mendoza MA, Roca M. Comparison of extracorporeal shock wave therapy with botulinum toxin type $A$ in the treatment of plantar fasciitis. Disabil Rehabil. 2016 10/15;38(21):2114-21.

62. Eslamian F, Shakouri SK, Jahanjoo F, Hajialiloo M, Notghi F. Extra corporeal shock wave therapy versus local corticosteroid injection in the treatment of chronic plantar fasciitis, a single blinded randomized clinical trial. Pain Med. 2016 Sep; 17(9):1722-31.

63. Ulusoy A, Cerrahoglu L, Orguc S. Magnetic resonance imaging and clinical outcomes of laser therapy, ultrasound therapy, and extracorporeal shock wave therapy for treatment of plantar fasciitis: A randomized controlled trial. J Foot Ankle Surg. 2017 Jul - Aug;56(4):762-7.

64. Bagcier F, Yilmaz N. The impact of extracorporeal shock wave therapy and dry needling combination on pain and functionality in the patients diagnosed with plantar fasciitis. J Foot Ankle Surg. 2020 Jul - Aug;59(4):689-93. 
65. Grecco MV, Brech GC, Greve JM. One-year treatment follow-up of plantar fasciitis: Radial shockwaves vs. conventional physiotherapy. Clinics (Sao Paulo). 2013;68(8): 1089-95.

66. Akinoglu B, Köse N, Kirdi N, Yakut Y. Comparison of the acute effect of radial shock wave therapy and ultrasound therapy in the treatment of plantar fasciitis: A randomized controlled study. Pain Med. 2017 12/01;18(12):2443-52.

67. Savovic J, Weeks L, Sterne JA, Turner L, Altman DG, Moher D, et al. Evaluation of the cochrane collaboration's tool for assessing the risk of bias in randomized trials: Focus groups, online survey, proposed recommendations and their implementation. Syst Rev. 2014 Apr 15;3:37,4053-3-37.

68. Hsiao MY, Hung CY, Chang KV, Chien KL, Tu YK, Wang TG. Comparative effectiveness of autologous blood-derived products, shock-wave therapy and corticosteroids for treatment of plantar fasciitis: A network meta-analysis. Rheumatology (Oxford). 2015 Sep;54(9):1735-43.

69. Singh P, Madanipour S, Bhamra JS, Gill I. A systematic review and metaanalysis of platelet-rich plasma versus corticosteroid injections for plantar fasciopathy. Int Orthop. 2017 Jun;41(6):1169-81.

70. Roerdink RL, Dietvorst M, van der Zwaard B, van der Worp $H$, Zwerver J. Complications of extracorporeal shockwave therapy in plantar fasciitis: Systematic review. Int J Surg. 2017 Oct;46:133-45.

71. Yin MC, Ye J, Yao M, Cui XJ, Xia Y, Shen QX, et al. Is extracorporeal shock wave therapy clinical efficacy for relief of chronic, recalcitrant plantar fasciitis? A systematic review and meta-analysis of randomized placebo or active-treatment controlled trials. Arch Phys Med Rehabil. 2014 Aug;95(8):1585-93.

72. Chang KV, Chen SY, Chen WS, Tu YK, Chien KL. Comparative effectiveness of focused shock wave therapy of different intensity levels and radial shock wave therapy for treating plantar fasciitis: A systematic review and network metaanalysis. Arch Phys Med Rehabil. 2012 Jul;93(7):1259-68. 
73. Whittaker GA, Munteanu SE, Menz HB, Landorf KB. Should foot orthoses be used for plantar heel pain? Br J Sports Med. 2018 Oct;52(19):1224-5.

74. Rasenberg N, Riel H, Rathleff MS, Bierma-Zeinstra SMA, van Middelkoop M. Efficacy of foot orthoses for the treatment of plantar heel pain: A systematic review and meta-analysis. $\mathrm{Br}$ J Sports Med. 2018 Mar 19.

75. Xu R, Wang Z, Ren Z, Ma T, Jia Z, Fang S, et al. Comparative study of the effects of customized 3D printed insole and prefabricated insole on plantar pressure and comfort in patients with symptomatic flatfoot. Med Sci Monit. 2019 May $12 ; 25: 3510-9$.

76. Bishop C, Thewlis D, Hillier S. Custom foot orthoses improve first-step pain in individuals with unilateral plantar fasciopathy: A pragmatic randomised controlled trial. BMC Musculoskelet Disord. 2018 Jul 18;19(1):222,018-2131-6.

77. Lai T, Ma H, Lee M, Chen P, Ku M. Ultrasonography and clinical outcome comparison of extracorporeal shock wave therapy and corticosteroid injections for chronic plantar fasciitis: A randomized controlled trial. J Musculoskelet Neuronal Interact. 2018 03/01;18(1):47-54.

78. Li X, Zhang L, Gu S, Sun J, Qin Z, Yue J, et al. Comparative effectiveness of extracorporeal shock wave, ultrasound, low-level laser therapy, noninvasive interactive neurostimulation, and pulsed radiofrequency treatment for treating plantar fasciitis: A systematic review and network meta-analysis. Medicine (Baltimore). 2018 10;97(43):e12819-.

79. Macias DM, Coughlin MJ, Zang K, Stevens FR, Jastifer JR, Doty JF. Low-level laser therapy at $635 \mathrm{~nm}$ for treatment of chronic plantar fasciitis: A placebocontrolled, randomized study. J Foot Ankle Surg. 2015 Sep-Oct;54(5):768-72.

80. Ordahan B, Karahan AY, Kaydok E. The effect of high-intensity versus lowlevel laser therapy in the management of plantar fasciitis: A randomized clinical trial. Lasers Med Sci. 2018 Aug;33(6):1363-9. 
81. Ball EM, McKeeman HM, Patterson C, Burns J, Yau WH, Moore OA, et al. Steroid injection for inferior heel pain: A randomised controlled trial. Ann Rheum Dis. 2013 Jun;72(6):996-1002.

82. Brinks A, Koes BW, Volkers AC, Verhaar JA, Bierma-Zeinstra SM. Adverse effects of extra-articular corticosteroid injections: A systematic review. BMC Musculoskelet Disord. 2010 Sep 13;11:206,2474-11-206.

83. Lee HS, Choi YR, Kim SW, Lee JY, Seo JH, Jeong JJ. Risk factors affecting chronic rupture of the plantar fascia. Foot Ankle Int. 2014 Mar;35(3):258-63.

84. Mellor R, Bennell K, Grimaldi A, Nicolson P, Kasza J, Hodges P, et al. Education plus exercise versus corticosteroid injection use versus a wait and see approach on global outcome and pain from gluteal tendinopathy: Prospective, single blinded, randomised clinical trial. Br J Sports Med. 2018 Nov;52(22):1464-72.

85. Coombes BK, Bisset L, Brooks P, Khan A, Vicenzino B. Effect of corticosteroid injection, physiotherapy, or both on clinical outcomes in patients with unilateral lateral epicondylalgia: A randomized controlled trial. JAMA. 2013 Feb $6 ; 309(5): 461-9$.

86. Chen C, Lee M, Lin C, Chang C, Lin C. Comparative efficacy of corticosteroid injection and non-invasive treatments for plantar fasciitis: A systematic review and meta-analysis. Sci Rep. 2018 03/05;8(1):4033-.

87. Uğurlar M, Sönmez MM, Uğurlar ÖY, Adıyeke L, Yıldırım $H$, Eren OT. Effectiveness of four different treatment modalities in the treatment of chronic plantar fasciitis during a 36-month follow-up period: A randomized controlled trial. J Foot Ankle Surg. 2018 09/20;57(5):913-8.

88. Santos BD, Correa LA, Teixeira Santos L, Filho NA, Lemos T, Nogueira LA. Combination of hip strengthening and manipulative therapy for the treatment of plantar fasciitis: A case report. J Chiropr Med. 2016 Dec;15(4):310-3.

89. Lee JH, Park JH, Jang WY. The effects of hip strengthening exercises in a patient with plantar fasciitis: A case report. Medicine (Baltimore). 2019 Jun; 98(26):e16258. 
90. Wheeler PC, Tattersall C. Extracorporeal shockwave therapy plus rehabilitation for patients with chronic plantar fasciitis might reduce pain and improve function but still not lead to increased activity: A case-series study with multiple outcome measures. J Foot Ankle Surg. 2018 Mar - Apr;57(2):339-45.

91. Wang YC, Chen SJ, Huang PJ, Huang HT, Cheng YM, Shih CL. Efficacy of different energy levels used in focused and radial extracorporeal shockwave therapy in the treatment of plantar fasciitis: A meta-analysis of randomized placebo-controlled trials. J Clin Med. 2019 Sep 19;8(9):10.3390/jcm8091497.

92. Smith BE, Hendrick P, Bateman M, Holden S, Littlewood C, Smith TO, et al. Musculoskeletal pain and exercise-challenging existing paradigms and introducing new. Br J Sports Med. 2018 Jun 20.

93. Littlewood C, Malliaras P, Mawson S, May S, Walters S. Development of a selfmanaged loaded exercise programme for rotator cuff tendinopathy. Physiotherapy. 2013 Dec;99(4):358-62.

94. McLean SM, Burton M, Bradley L, Littlewood C. Interventions for enhancing adherence with physiotherapy: A systematic review. Man Ther. 2010 Dec; 15(6):514-21.

95. Creswell JW, Creswell JD. Research design: Qualitative, quantitative and mixed methods approaches. 5th; International student ed. Los Angeles: Sage; $2018 ; 2018$.

96. Whittaker GA, Munteanu SE, Menz HB, Bonanno DR, Gerrard JM, Landorf KB. Corticosteroid injection for plantar heel pain: A systematic review and metaanalysis. BMC Musculoskelet Disord. 2019 Aug 17;20(1):378,019-2749-z.

97. Wu FL, Shih YF, Lee SH, Luo HJ, Wang WT. Can short-term effectiveness of anti-pronation taping predict the long-term outcomes of customized foot orthoses: Developing predictors to identify characteristics of patients with plantar heel pain likely to benefit from customized foot orthoses. BMC Musculoskelet Disord. 2019 May $31 ; 20(1): 264,019-2648-3$. 
98. Moyne-Bressand S, Dhieux C, Dousset E, Decherchi P. Effectiveness of foot biomechanical orthoses to relieve patients suffering from plantar fasciitis: Is the reduction of pain related to change in neural strategy? BIOMED RES INT. 2018 12/12:1-17.

99. Whittaker GA, Munteanu SE, Menz HB, Tan JM, Rabusin CL, Landorf KB. Foot orthoses for plantar heel pain: A systematic review and meta-analysis. $\mathrm{Br}$ J Sports Med. 2018 Mar;52(5):322-8.

99. Riel H, Olesen JL, Jensen MB, Vicenzino B, Rathleff MS. Heavy-slow resistance training in addition to an ultrasound-guided corticosteroid injection for individuals with plantar fasciopathy: A feasibility study. Pilot Feasibility Stud. 2019 Aug 24;5:105,019-0489-3. eCollection 2019.

100. Zwerver J, Waugh C, van der Worp H, Scott A. Can shockwave therapy improve tendon metabolism? Adv Exp Med Biol. 2016;920:275-81.

101. Malliaropoulos N, Crate G, Meke M, Korakakis V, Nauck T, Lohrer H, et al. Success and recurrence rate after radial extracorporeal shock wave therapy for plantar fasciopathy: A retrospective study. Biomed Res Int. 2016;2016:9415827.

102. Plaza-Manzano G, Rios-Leon M, Martin-Casas P, Arendt-Nielsen L, Fernandezde-Las-Penas C, Ortega-Santiago R. Widespread pressure pain hypersensitivity in musculoskeletal and nerve trunk areas as a sign of altered nociceptive processing in unilateral plantar heel pain. J Pain. 2019 Jan;20(1):60-7.

103. Drake C, Mallows A, Littlewood C. Psychosocial variables and presence, severity and prognosis of plantar heel pain: A systematic review of cross-sectional and prognostic associations. Musculoskeletal Care. 2018 09;16(3):329-38.

104. Cotchett MP, Whittaker G, Erbas B. Psychological variables associated with foot function and foot pain in patients with plantar heel pain. Clin Rheumatol. 2015 May;34(5):957-64.

105. Cotchett M, Lennecke A, Medica VG, Whittaker GA, Bonanno DR. The association between pain catastrophising and kinesiophobia with pain and function in people with plantar heel pain. Foot (Edinb). 2017 Aug;32:8-14. 
106. Mc Auliffe S, Synott A, Casey H, Mc Creesh K, Purtill H, O'Sullivan K. Beyond the tendon: Experiences and perceptions of people with persistent achilles tendinopathy. Musculoskelet Sci Pract. 2017 Jun;29:108-14.

107. Harutaichun $\mathrm{P}$, Boonyong S, Pensri P. Predictors of plantar fasciitis in thai novice conscripts after 10-week military training: A prospective study. Phys Ther Sport. 2019 Jan;35:29-35.

108. Harutaichun P, Pensri P, Boonyong S. Physical and psychological predictors on pain intensity in conscripts with plantar fasciitis. Braz J Phys Ther. 2019 Mar 11.

109. Beeson P. Plantar fasciopathy: Revisiting the risk factors. Foot Ankle Surg. 2014 Sep;20(3):160-5.

110. Valizadeh MA, Afshar A, Hassani E, Tabrizi A, Rezalo S, Dourandish N. Relationship between anthropometric findings and results of corticosteroid injections treatment in chronic plantar heel pain. Anesth Pain Med. 2018 Feb $17 ; 8(1):$ e64357.

111. Akinoglu B, Kose N. A comparison of the acute effects of radial extracorporeal shockwave therapy, ultrasound therapy, and exercise therapy in plantar fasciitis. J Exerc Rehabil. 2018 Apr 26;14(2):306-12.

112. Eun SS, Chachan S, Lee SH. Effectiveness of a double air-cushioned shoe compared with physiotherapy in the treatment of plantar fasciitis. Biomed Res Int. 2020 04/02;2020:9468302.

113. Greve JM, Grecco MV, Santos-Silva PR. Comparison of radial shockwaves and conventional physiotherapy for treating plantar fasciitis. Clinics (Sao Paulo). 2009;64(2):97-103.

114. Krukowska J, Wrona J, Sienkiewicz M, Czernicki J. A comparative analysis of analgesic efficacy of ultrasound and shock wave therapy in the treatment of patients with inflammation of the attachment of the plantar fascia in the course of calcaneal spurs. Arch Orthop Trauma Surg. 2016 Sep;136(9):1289-96. 
115. Melegati G, Tornese D, Bandi M, Caserta A. The influence of local steroid injections, body weight and the length of symptoms in the treatment of painful subcalcaneal spurs with extracorporeal shock wave therapy. Clin Rehabil. 2002 $11 ; 16(7): 789-94$.

116. Porter MD, Shadbolt B. Intralesional corticosteroid injection versus extracorporeal shock wave therapy for plantar fasciopathy. Clin J Sport Med. 2005 May;15(3):119-24. 
